\title{
Therapeutic Applications of Antimicrobial Silver-Based Biomaterials in Dentistry
}

\author{
Qiyu Wang',*, Yu Zhang $\mathbb{D}^{1, *}$, Qiang Li $\mathbb{D}^{2, *}$, Li Chen', Hui Liu', Meng Ding², Heng Dong $\mathbb{D}^{\prime}$, Yongbin Mou' \\ 'Department of Oral Implantology, Nanjing Stomatological Hospital, Medical School of Nanjing University, Nanjing, People's Republic of China; \\ ${ }^{2}$ Central Laboratory, Nanjing Stomatological Hospital, Medical School of Nanjing University, Nanjing, People's Republic of China \\ *These authors contributed equally to this work
}

Correspondence: Yongbin Mou; Heng Dong, Department of Oral Implantology, Nanjing Stomatological Hospital, Medical School of Nanjing University, \#30 Zhongyang Road, Nanjing, 210008, People's Republic of China, Tel +86 25 83620236, Fax +86 2583620202 , Email yongbinmou@।63.com; dongheng90@smail.nju.edu.cn

\begin{abstract}
Microbial infection accounts for many dental diseases and treatment failure. Therefore, the antibacterial properties of dental biomaterials are of great importance to the long-term results of treatment. Silver-based biomaterials (AgBMs) have been widely researched as antimicrobial materials with high efficiency and relatively low toxicity. AgBMs have a broad spectrum of antimicrobial properties, including penetration of microbial cell membranes, damage to genetic material, contact killing, and dysfunction of bacterial proteins and enzymes. In particular, advances in nanotechnology have improved the application value of AgBMs. Hence, in many subspecialties of dentistry, AgBMs have been researched and employed, such as caries arresting or prevention, root canal sterilization, periodontal plaque inhibition, additives in dentures, coating of implants and anti-inflammatory material in oral and maxillofacial surgery. This paper aims to provide an overview of the application approaches of AgBMs in dentistry and present better guidance for oral antimicrobial therapy via the development of AgBMs.
\end{abstract}

Keywords: silver, antimicrobial, dentistry, oral biofilm formation, biomaterials, nanotechnology

\section{Introduction}

Tissue surfaces of the oral cavity provide an ideal environment for attachment and formation of plaque biofilms, which are a crucial cause of dental caries, gingivitis or periodontitis, denture stomatitis, and other dental diseases. These bacterial or fungal communities cause infections by protecting pathogenic microbes from medical treatment and evading host defense responses. Dental plaque biofilms provide a reservoir for the growth and spread of multidrug-resistant bacteria and pose threats to immunocompromised patients. ${ }^{1}$ Despite the clinical use of antibiotics and other antimicrobial drugs, multidrug resistance remains an intractable problem.

The antibacterial properties of silver have been known since ancient times. Silver-based biomaterials (AgBMs) have been employed in several areas of dentistry due to their broad-spectrum antimicrobial properties (Figure 1). AgBMs include various forms of materials, such as traditional amalgam silver, silver-citrate, silver diamine fluoride, colloidal silver, and silver-based nanoparticles (AgNPs). ${ }^{2}$ AgBMs have been proven to be effective against most oral pathogens, including Streptococcus mutans (S. mutans), Streptococcus mitis (S. mitis), Streptococcus oralis (S. oralis), Streptococcus sanguis (S. sanguis), Porphyromonas gingivalis (P. gingivalis), Staphylococcus aureus (S. aureus), Candida albicans (C. albicans), Escherichia faecalis (E. faecalis) and Escherichia coli (E. coli). ${ }^{3}$ The effective bactericidal property of AgBMs arrests the attachment and formation of biofilms, which is essential for the application of dental materials.

The advancement of nanotechnology brings tremendous amounts of new materials with unique properties. Among all kinds of AgBMs, AgNPs have received the most attention for their outstanding antimicrobial properties against bacteria, fungi, and enveloped viruses. ${ }^{4}$ AgNPs are defined as elemental silver particles in size at a nanometer scale (1 nm to $\left.100 \mathrm{~nm}\right) .{ }^{5}$ Compared to the particles in traditional colloidal silver, AgNPs are more consistent in size and shape, which means 


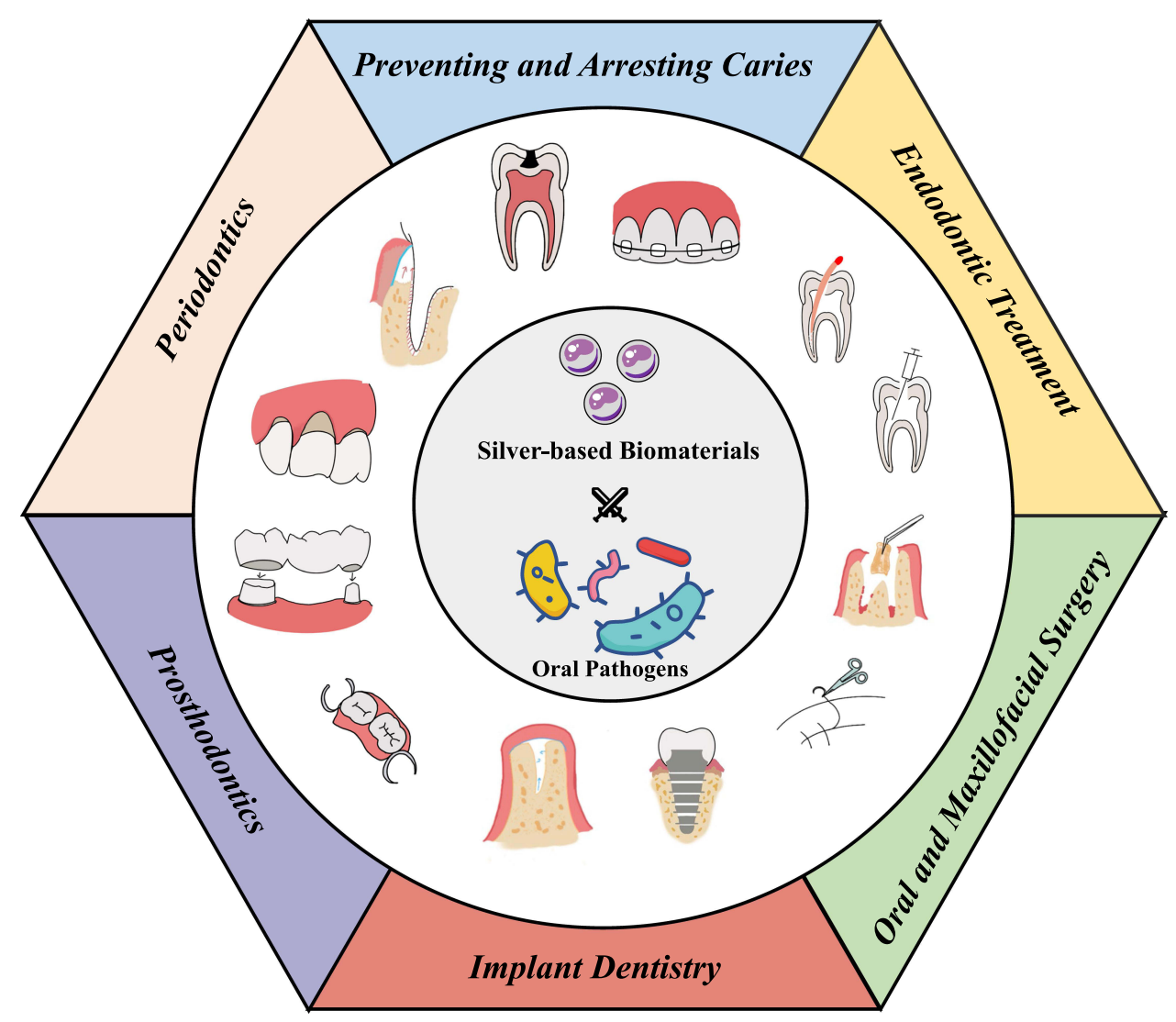

Figure I A schematic illustration of the medical functions and therapeutic applications of antimicrobial silver-based biomaterials in dentistry.

consistency in properties. The inner core of most AgNPs is metallic silver and the outer shell is surface oxide or sulfide layers. ${ }^{6}$ Silver ions are released in the process of the oxidation and dissolution of the surface layer of $\mathrm{Ag}_{2} \mathrm{O}$. $^{7}$ The existing synthesis methods can be divided into "top-down" and "bottom-up" approaches, namely, the "cutting" process from bulk silver to nanosize or synthesis from molecular, atomic, and ionic components. ${ }^{8}$

At the nanoscale, most of the atoms of nanomaterials are surface atoms, which dramatically alters their properties. As a kind of nanomaterial, AgNPs exhibit unique properties. Featuring their ultrasmall size, large surface area to mass ratio, and enhanced chemical reactions, AgNPs have broad prospects in antimicrobial therapy.$^{9}$ Thus, AgNPs have been proven to be powerful weapons against multidrug-resistant bacteria. ${ }^{10}$ Additionally, decreased size improves wear resistance, which is valuable in dentistry. ${ }^{11}$ Furthermore, an increased surface/volume ratio results in higher surface reactions and stronger bond strength of mechanical interlock with the polymer matrix. ${ }^{12}$ Besides, AgNPs could improve the aesthetics of dental materials. The diameter of nanoparticles is smaller than the wavelength of visible light (400 $\mathrm{nm}$ to $800 \mathrm{~nm}$ ), which means that more transparent dental materials can be made. ${ }^{13,14}$

In this review, we systematically discuss the advancement and application of antimicrobial AgBMs in dentistry with emphasis on the mechanism, biosecurity and clinical application.

\section{Characteristics and Performance of AgBMs}

\section{Category of AgBMs}

As a promising material in the antibacterial field, AgNPs have been extensively studied. According to chemical properties, $\mathrm{AgBMs}$ can be divided into metallic silver, silver salt (eg, $\mathrm{AgNO}_{3}$ and silver sulfadiazine), silver oxides (eg, $\mathrm{Ag}_{2} \mathrm{O}$ ) and composite materials (eg, silver zeolite). According to the size scale, AgBMs can be divided into bulk materials, traditional colloids and AgNPs. More specifically, AgNPs can be divided into metallic AgNPs and their ionic 
counterparts. Ionic AgNPs are nanoparticles of insoluble silver compounds, such as silver bromide (AgBr NPs), silver vanadate $\left(\mathrm{AgVO}_{3} \mathrm{NPs}\right)$ and silver oxide $\left(\mathrm{Ag}_{2} \mathrm{O} \mathrm{NPs}\right) .{ }^{15-17}$

\section{Antimicrobial Mechanisms of AgBMs}

The antibacterial mechanisms of silver, especially AgNPs, has been a major issue in numerous scientific publications. AgBMs have similar killing mechanisms on bacteria and fungi. ${ }^{13,18}$ However, the exact molecular mechanisms of action remain unclear. The potential mechanisms of the antimicrobial effect of AgBMs are described below (Figure 2).

AgBMs exert suppression on bacterial metabolism. The common mechanism of AgBM is attributed to the gradual release of silver ions $\left(\mathrm{Ag}^{+}, \mathrm{Ag}^{2+}, \mathrm{Ag}^{3+}\right)$ in the majority of publications. ${ }^{19}$ Furthermore, it has been reported that silver ions have an affinity for multiple functional groups, such as phosphate, carboxyl, amino, and thiol groups, which disturbs those biological functions. More specifically, silver ions first affect the function of proteins and enzymes. Yamanaka et al confirmed that the 30S subunit and succinyl-CoA synthase of the ribosome were particularly inhibited by silver in prokaryotic cells such as E. coli. The former participates in the decoding of mRNA, while the latter is an important part of the glucose pathway and the tricarboxylic acid cycle (TCA cycle), which is crucial for the survival of cells. ${ }^{20}$ Thus, the interruption of adenosine triphosphate (ATP) finally results in bacterial death. Gordon et al suggested that thiol groups (eg, glutathione and cysteine) are the main targets that determine the antimicrobial properties of AgBMs. Their theory was confirmed because the toxicity of $\mathrm{AgNO}_{3}$ to succinate dehydrogenase (from the respiratory chain) and aconitase (from the TCA cycle) could be alleviated by the addition of glutathione. ${ }^{21}$ Therefore, the bactericidal mechanism of AgNPs is regarded as a "ion carrier" through the cytomembrane. Accordingly, the size of AgNPs is designed to be as small as possible because a larger surface-to-volume ratio means more efficient release of silver ions, namely, greater antimicrobial activity. ${ }^{22-24}$ In addition, silver ions adhere to ribosomes and inhibit protein synthesis by disturbing their conformation after entering the cytoplasm. ${ }^{25}$

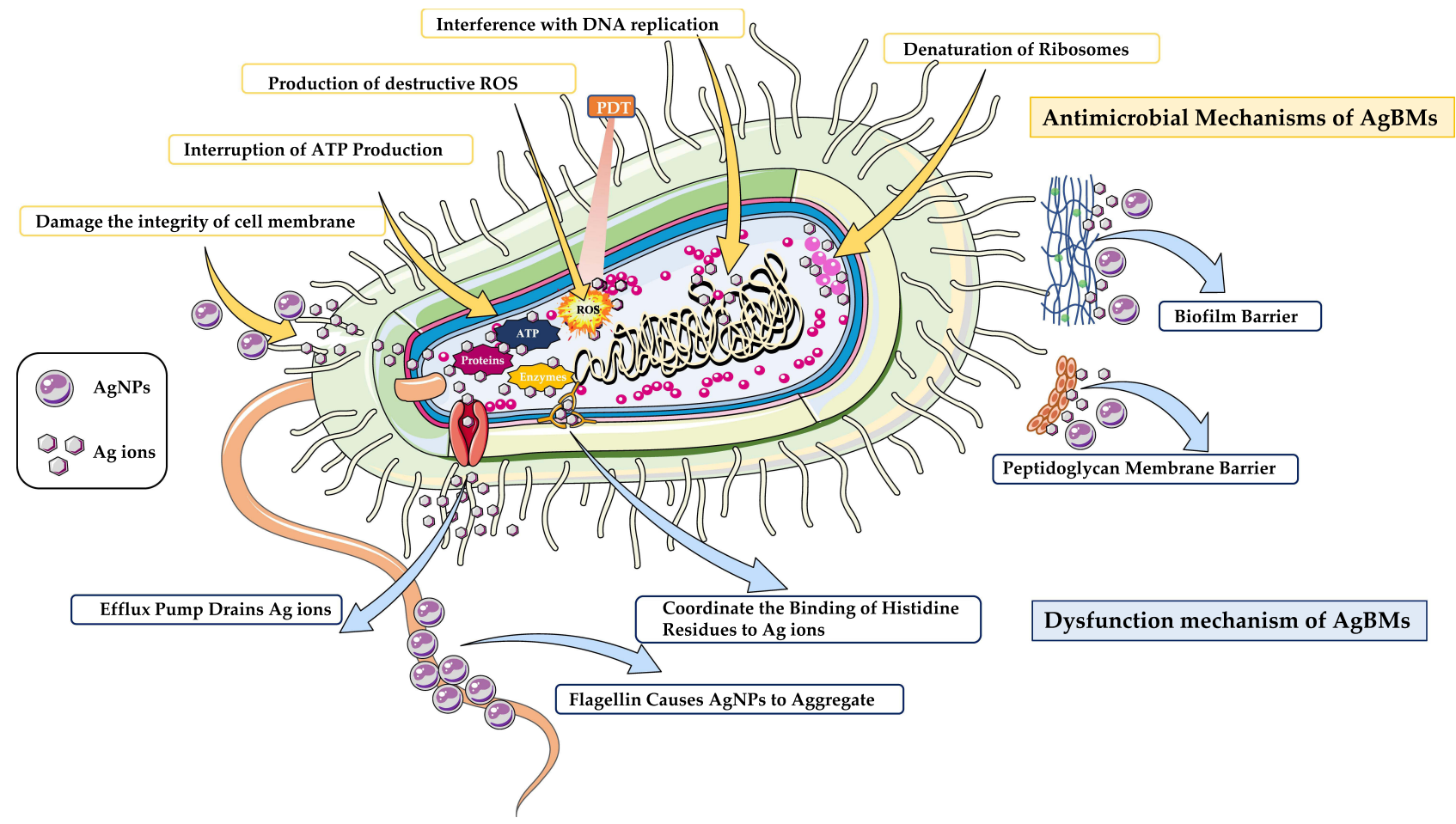

Figure 2 Antimicrobial and Dysfunction Mechanisms of AgBMs. Antimicrobial mechanisms of AgBMs (yellow frame) include destruction of the cell wall and cytoplasmic membrane, interruption of ATP production, production of destructive chemicals, interference with DNA replication and denaturation of ribosomes. The dysfunction mechanisms of $\mathrm{AgBMs}$ (blue frame) include efflux pump draining $\mathrm{Ag}^{+}$, flagellin aggregating $\mathrm{AgNPs}$, coordinating the binding of histidine residues to $\mathrm{Ag}^{+}$, peptidoglycan membrane barrier, and biofilm barrier.

Abbreviations: ATP, adenosine triphosphate; DNA, deoxyribonucleic acid; ROS, reactive oxygen species; PDT, photodynamic therapy. 
AgBMs cause the accumulation of chemicals that damage cellular components, such as proteins, DNA and lipids. The production of excessive reactive oxygen species (ROS) induced by silver ions has long been observed and regarded as an important bactericidal mechanism..$^{21,26}$ The specific mechanism of how silver ions ignite the Fenton reaction remains controversial. ${ }^{18}$ It has been proposed that the exhaustion of thiol groups by silver ions leads to the accumulation of ROS because thiol groups in glutathione and cysteine are essential in the homeostasis antioxidant system. ${ }^{27}$ Interestingly, the release of silver ions is not the only method by which AgNPs ignite the production of ROS. AgNPs and silver nanoclusters (AgNCs) are also employed in photodynamic therapy (PDT) as promising photosensitizers. Photosensitizers produce ROS, such as hydroxyl radicals, superoxides, or singlet oxygen $\left({ }^{1} \mathrm{O}_{2}\right)$, when they are irradiated by light whose wavelength matches them. ${ }^{26}$ In the area of sterilization, common photosensitizers are limited by their cytotoxicity to mammalian cells. With the advancement of nanotechnology, AgNPs serve as a novel photosensitizer for the following reasons:(1) little cytotoxicity to mammalian cells,(2) intracellularly induced photosensitivity, and(3) silver ions released simultaneously. ${ }^{28}$ Therefore, AgNPs have incomparable advantages over traditional photosensitizers.

AgBMs damage the integrity of the cell membrane due to their physical properties. First, silver ions can cause depolarization of the cellular membrane due to electrostatic interactions with membrane phospholipids and proteins, resulting in destabilization of the cytomembrane. ${ }^{29}$ Notably, AgNPs have unique antibacterial mechanisms that are totally different from those of other AgBMs. Direct contact with uncharged nanoparticles can also rupture the bacterial cell membrane as a result of the physiochemical features of nanoparticles, such as surface topology, size, geometry and hydrophobicity, regardless of germ type. ${ }^{30,31}$ This "contact killing" mechanism has been employed to prolong antibacterial effects. For example, AgNPs immobilized on a material surface resist the formation of biofilms by rupturing the bacterial cell membrane and releasing silver ions simultaneously. ${ }^{32}$

\section{Dysfunction Mechanism of AgBMs}

Unlike ordinary antibiotics, silver activates multiple mechanisms and hits different targets within bacterial cells. Therefore, it is difficult for these microorganisms to develop adaptive resistance. The only fully silver-resistant strain known at present is $P$. stutzeri which is found in silver mines. ${ }^{16}$ Interestingly, some antisilver mechanisms of bacteria have been described and summarized in Figure 2: (1) the energy-dependent efflux pump is the most efficient antisilver method of bacteria. ${ }^{33,34}$ The sil gene on the Salmonella pMG101 plasmid was identified to encode the silver ejection system; (2) flagellin, a globular protein in the flagellum, is considered to be an anti-silver agent of gram-negative bacteria. It is speculated that flagellin causes AgNPs to aggregate as an adhesive protein, thereby eliminating the antimicrobial effect of AgNPs. This mechanism involves phenotypic changes and can be eliminated by flagellin inhibitors easily; ${ }^{35}$ (3) bacterial can coordinate the binding of histidine residues to silver ions. Microbes are usually susceptible to AgBM because of the lack of thiol groups. ${ }^{36}$ However, Salmonella has been observed to coordinate the binding of histidine residues to silver ions, as an alternative to thiol groups ${ }^{37}$ (4) gram-positive bacteria sequester silver in their peptidoglycan membrane, which explains why they are less sensitive than gram-negative bacteria; ${ }^{38}$ and (5) biofilms act as physical barriers. Its components, including nucleic acids, proteins, polysaccharides, and lipids, interact with AgBM through electrostatic interactions, hydrophobic interactions, hydrogen bond interactions, and van der Waals interactions, which reduces the antimicrobial activity of AgBM. ${ }^{39}$

Additionally, the precipitation reaction of silver ions with halogen is also an important cause of inactivation. Given that saliva and gingival crevicular fluid in the mouth are rich in $\mathrm{Cl}^{-}$, more researches are needed on the long-term antimicrobial effects of silver. ${ }^{34}$

\section{Biosafety Considerations of AgBMs}

It has been reported that the toxicity of silver ions to bacteria is comparable to that of human cells. ${ }^{36}$ During application, AgBMs are exposed to digestive mucosa and bone tissue. Meanwhile, there is also a risk of inhalation during chairside extracorporeal polishing operations. Considering that dental AgBMs may continue functioning in the oral environment for decades, it is essential to lower their toxicity to human cells. ${ }^{40}$

In regard to the specific types of AgBMs, soluble compounds are always more toxic than insoluble ones. For example, the $\mathrm{LD}_{50}$ of $\mathrm{AgNO}_{3}$ is estimated to be $28 \mathrm{mg} / \mathrm{kg}$, while that of $\mathrm{AgCl}$ is over $10 \mathrm{~g} / \mathrm{kg}$. ${ }^{16,41}$ Notably, it is not convenient to 
assess the toxicology of nanomaterials such as AgNPs with the traditional mass-only dose metric model. The cytotoxicity of AgNPs in mammalian cells depends on the nanoparticle size, shape, surface charge, dosage, oxidation state, agglomeration condition, and cell type. Generally, smaller AgNPs are more toxic due to the higher surface-to-volume ratio. ${ }^{42}$ Obviously, toxicity limits the application of certain types of AgNPs. For example, $\mathrm{Ag}_{2} \mathrm{O}$ nanoparticles $\left(\mathrm{Ag}_{2} \mathrm{O} \mathrm{NPs}\right)$ exhibit high toxicity to eukaryotic cells. Therefore, they are employed as antitumor materials instead of bactericidal agents despite their high efficiency of killing bacteria and protozoa. ${ }^{17}$

Generally, AgBMs are described as barely perceptible irritants because of the low concentration used in oral treatment. However, some atopic dermatitis can still be observed. ${ }^{9}$ There is no convincing research describing the absorption of silver in oral mucosa, while the absorption of silver into the blood has been demonstrated via ocular, uterine and nasal mucous membranes. ${ }^{43}$ Furthermore, silver can disrupt mitochondrial electron transport and induce apoptosis through an oxidative stress pathway, which has been demonstrated in liver and bronchial epithelial cells. ${ }^{44-46}$ Recordati et al observed slow clearance of silver and ultrastructural changes of the blood-brain barrier after oral administration of $1 \mathrm{mg} / \mathrm{kg}$ AgNPs and silver acetate in mice, without any treatment-related signs or effects on body and organ weights. ${ }^{47}$

However, the application of AgBMs still shows some risks, such as argyria. Argyria is an infrequent, silver-related disease, that presents as blue-gray discoloration of the skin due to silver deposition. According to recent research, Argyria is attributed to infusible precipitates. It was reported that silver serum levels below $300 \mu \mathrm{g} / \mathrm{L}$ were never observed to be related to Argyria. ${ }^{48}$ In addition, occupation exposure could occur in clinics while manipulating materials such as polishing composite restoration with no water coolant, which results in aerosols - with concentrations above $1 \times 10^{6}$ particles $/ \mathrm{cm}^{3}$ inhaled by dentists and patients. ${ }^{49,50}$ It has been reported that rodents exposed to inhaled silver particle aerosols have pulmonary inflammation and even asthma at concentrations of $0.11-0.75 \mathrm{mg} / \mathrm{m}^{3} .^{51}$

Compounds containing reduced thiol groups could significantly reduce the toxicity of silver ions. ${ }^{52}$ Given their limited size, bacterial cells contain far fewer low-molecular weight thiols than human cells, in addition to other antioxidant systems in human cells, such as cysteine-rich metallothionein. ${ }^{36}$ In vitro tests of silver toxicity are often closed systems where thiol content is much lower than that in the human body. Therefore, the toxicity of silver to human cells and its antimicrobial effect in vivo have been somewhat overestimated.

\section{Antimicrobial AgBMs Incorporated in Dental Materials Preventing and Arresting Caries}

Silver materials have been used for combating caries in various forms. For instance, silver could be added to restorative materials in case secondary caries occurs. ${ }^{53}$ AgNPs can also be added to adhesives and acrylic resins coated onto the surfaces of orthodontic appliances to prevent dental demineralization caused by bacteria or accumulation. ${ }^{54}$ In addition, daubing- or gargling-related medicine in the oral cavity is another method utilizing the antimicrobial properties of silver ions. ${ }^{55-58}$

\section{Dental Filling Material}

Early in 1985, the antimicrobial properties of silver amalgam were proven, as it gives off silver ions. ${ }^{59}$ An in vitro study carried out by Hegde et al showed that silver amalgam had a marked inhibitory effect better than glass ionomer cement (GIC) and composites. ${ }^{60}$ Later studies introduced a novel category of resins incorporated with AgBMs (Figure 3), which could exert extra antimicrobial effects, particularly against $\mathrm{S}$. mutans. ${ }^{61} \mathrm{Jia}$ et al synthesized $\mathrm{Zn}$-Ag-loaded nano- $\mathrm{SiO}_{2}$ specimens, which can be added into dental resin-based materials to enhance their antimicrobial properties. ${ }^{62}$ Kasraei et al reported that composite resins containing AgNPs exhibited antimicrobial activity against S. mutans and Lactobacillus. ${ }^{63}$ Suggested mass fractions vary based on the specific auxiliary material used, while consensus is that mass fractions larger than $1 \mathrm{wt} \%$ is not recommended due to the variation of mechanical properties and biocompatibility. ${ }^{64-67}$

The addition of AgNPs (250 ppm) to primers could improve the antimicrobial effect, with no effect on bond strength or the biocompatibility of adhesives. Furthermore, the combination of AgNP and primer preserves the interface between tooth and adhesive, extending the utility time of dental restorations. ${ }^{68}$ 


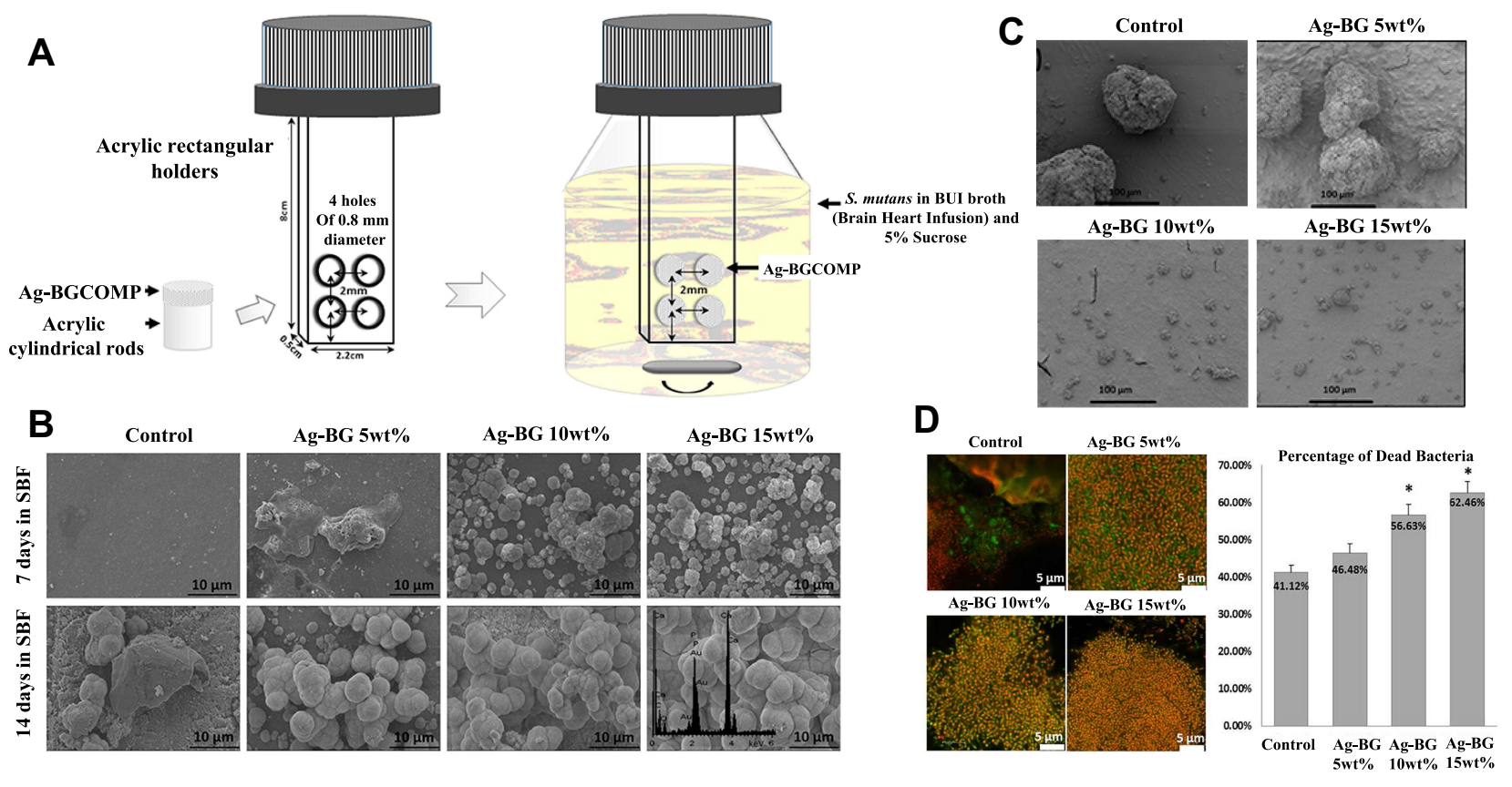

Figure 3 The AgBM was incorporated into resin composite. (A) Schematic illustration of biofilm formation by S. mutans on the surface of AgBM. (B) SEM images of the surface morphology of the AgBM specimens after immersion. (C) SEM images of the biofilm formed on the surface of the specimens. (D) CLSM representative images of the live and dead bacteria in the biofilms formed on the surface of the AgBM. *Shows the statistical significant difference. Reproduced with permission from Chatzistavrou X, Lefkelidou A, Papadopoulou L, et al. Bactericidal and Bioactive Dental Composites. Front Physiol. 2018;9:103. Copyright (C) 2018 Chatzistavrou, Lefkelidou, Papadopoulou, Pavlidou, Paraskevopoulos, Fenno, Flannagan, González-Cabezas, Kotsanos and Papagerakis. This is an open-access article distributed under the terms of the Creative Commons Attribution License (CC BY). ${ }^{61}$

\section{Orthodontic Appliance}

Etching is an essential process before adhering orthodontic brackets onto the teeth, which results in potent caries and white spot lesions (WSLs). ${ }^{69}$ WSLs may develop since the beginning of the treatment. ${ }^{70}$ Silver is utilized as an additive in orthodontic adhesive and coating of orthodontic brackets. It has been reported that caries around orthodontic retainers could be prevented if AgNPs were incorporated into composite resin. ${ }^{71}$ Considering enamel remineralization, some researchers confirmed that orthodontic resin modified by a certain concentration of AgNPs (1 wt\%) prevents WSL formation more efficiently (Figure 4$){ }^{72}$ In addition, orthodontic brackets coated with titanium oxide mixed with $\mathrm{Ag}$ could significantly reduce the adhesion of $S$. mutans and P. gingivalis, and biofilm formation. ${ }^{73,74}$

\section{Caries Treatment}

Inspired by the marked antimicrobial property of AgNPs, Haghgoo et al suggested that dental varnishes supplemented with AgNPs show good cariostatic efficacy. ${ }^{75}$ Silver diamine fluoride (SDF), approved by the US Food and Drug Administration (FDA), is a solution used for arresting caries or preventing potential lesions, and contains ionic silver, fluoride, and ammonia. ${ }^{76}$ It has been widely used in the prevention of early childhood caries (ECC) due to its effective, safe, painless, inexpensive and timely properties. ${ }^{77} \mathrm{SDF}$ exhibited significantly higher caries arrest rates than fluoride varnish, GIC and cross tooth-brushing technique (CTT) ${ }^{78-80}$ It has been claimed that $38 \%$ SDF solution was the most effective dose for arresting advanced cavitated caries, ranging from moderate to high certainty, if applied biannually. ${ }^{81}$ However, the precipitation of silver byproducts in dental tissues stains the lesions and soft tissue black.

Although many studies have suggested that the stain on lesions and gingival tissue could fade gradually at the start of 6 months after treatment, the stain trace is a limitation for the use of SDF in the anterior aesthetic area. ${ }^{82,83}$ A doubleblind clinical trial evaluated the cariostatic efficacy of 5\% AgNP-incorporated sodium fluoride (NSSF) and 38\% SDF in primary teeth, suggesting that they are equivalent in inhibiting dentine caries progression. NSSF is more economical and leaves no dark stains. ${ }^{83}$ Thus, NSSF has the potential to be an alternative to SDF owing to its antimicrobial effect and better aesthetic effect. ${ }^{55}$ 
A

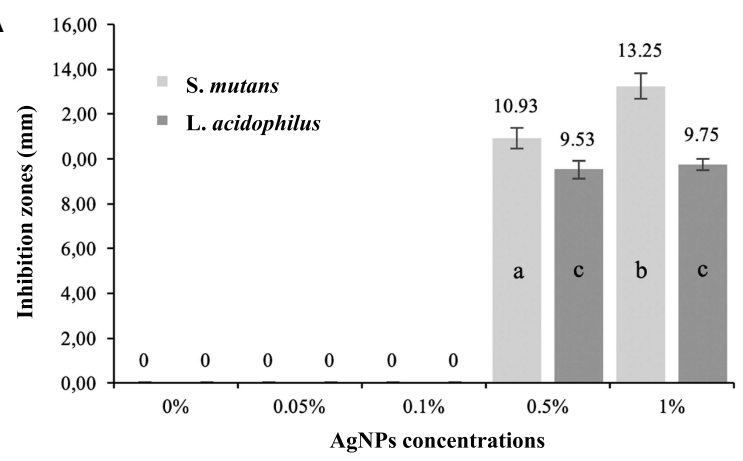

B

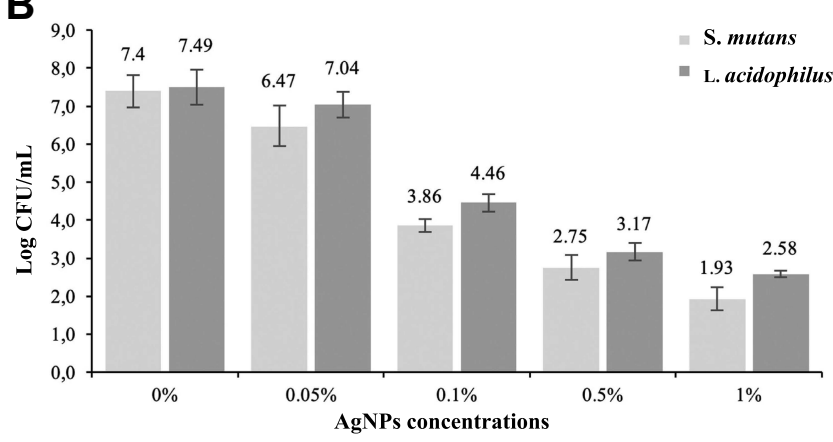

C

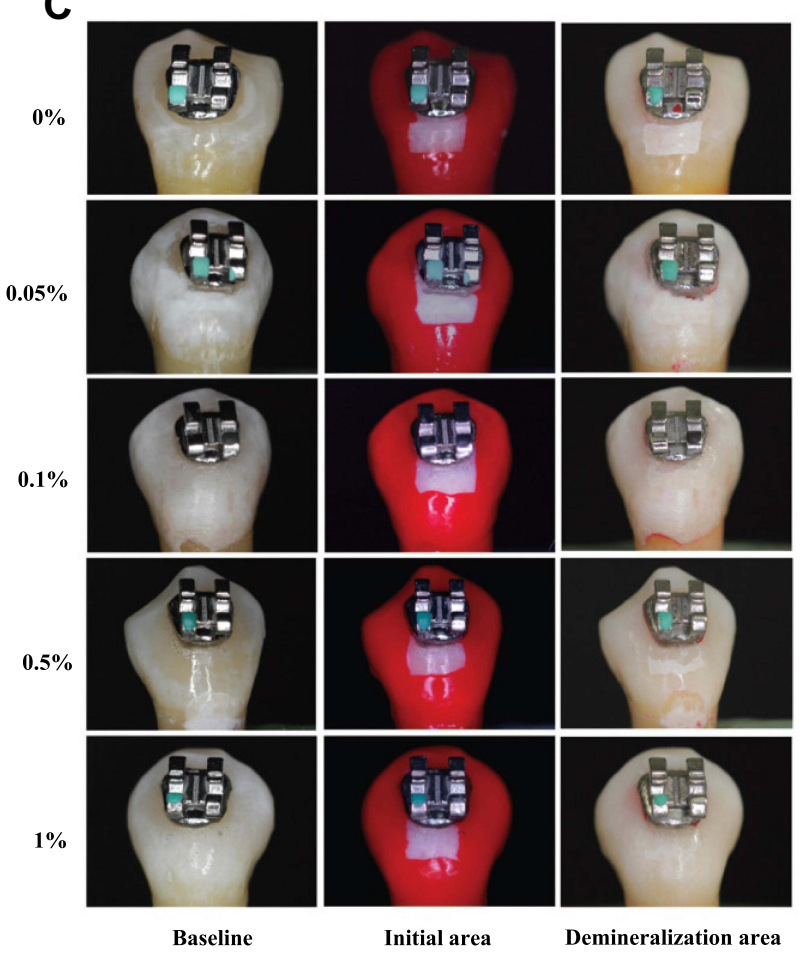

Figure 4 Orthodontic resin modified by a certain concentration of AgNPs. (A) Inhibition zones by AgNPs concentrations. (B) Colony-formation-units (Log CFU/mL) of S. mutans and L. acidophilus. (C) Tooths of the different groups exposed to microbiological caries induction. Reproduced with permission from Sánchez-Tito M, Tay LY. Antibacterial and white spot lesions preventive effect of an orthodontic resin modified with AgNPs. J Clin Exp Dent. 2021;।3(7):e685-e69I. (C) 202I Medicina Oral S.L. This is an open-access article distributed under the terms of the Creative Commons Attribution License, which permits unrestricted use, distribution, and reproduction in any medium, provided the original work is properly cited. $^{72}$

Bioactive glasses incorporated into dentifrices have proven the efficacy of treating demineralization and dental sensitivity because they can release therapeutic ions after dissolution, such as strontium $\left(\mathrm{Sr}^{2+}\right)$ and fluoride $\left(\mathrm{F}^{-}\right)$, to enhance remineralization. ${ }^{84}$

It is suggested that the combination of AgNPs and PDT has good cariostatic efficacy. It could be a method that minimizes microbial residue after mechanical removal of caries. Unlike traditional antimicrobial agents, PDT based on photosensitizers activated by light sources is noninvasive, repeatable, nonresistant, and penetrable. When provided with the right energy density, it may kill microorganisms in a matter of minutes. ${ }^{85}$

\section{Applications of AgBMs in Endodontic Treatment}

In the area of endodontics, AgBMs are applied to irrigation, medication, and addiction in sealer materials to improve their antimicrobial functions. ${ }^{86}$

\section{Irrigation}

Conventional endodontic irrigants include chlorhexidine (CHX), ethylenediaminetetraacetic acid (EDTA) and sodium hypochlorite ( $\mathrm{NaClO}$ ). Their limitations are cytotoxicity to periapical tissue or inadequate removal of bacterial biofilms and smear layers. ${ }^{87}$ It was reported that AgNPs can serve as active ingredients in root canal irrigation solutions. ${ }^{88-90}$ Application of root canal irrigation solution with AgNPs resulted in superior antimicrobial effects (Figure 5A), reduced cytotoxicity and even enhanced fracture resistance of endodontically treated roots, compared to $2.5 \%$ sodium hypochlorite (Figure 5B). ${ }^{91}$ In addition, a new silver-citrate root canal irrigation solution (BioAKT ${ }^{\circledR}$ ) was introduced as a smear layer removal agent, which allows reliable sealer penetration at the apical portion of the root canal system and offers outstanding antimicrobial effects. ${ }^{92,93} \mathrm{SDF}$ was also reported as an adequate irrigation solution. ${ }^{94,95}$ Additionally, 
A
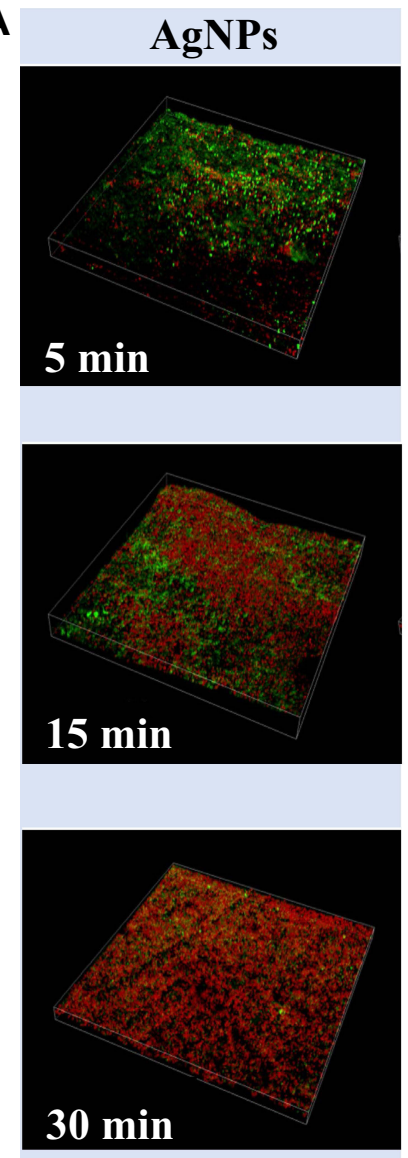

B

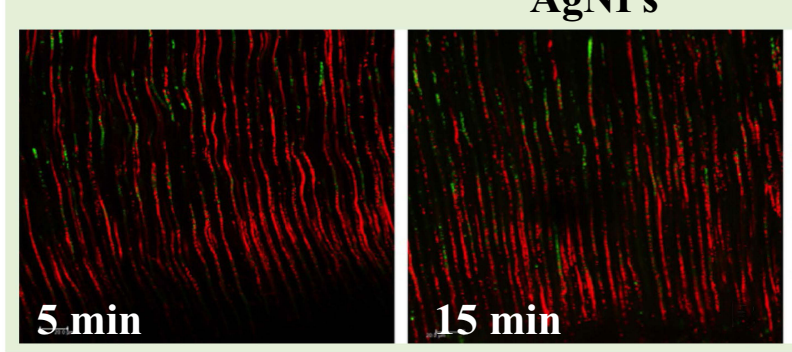

$2 \%$ chlorhexidine
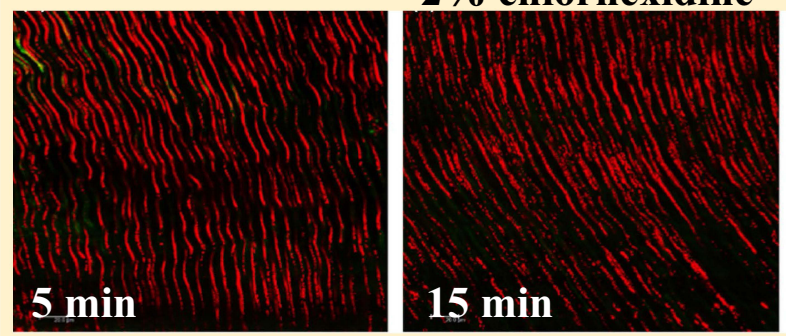

$30 \mathrm{~min}$

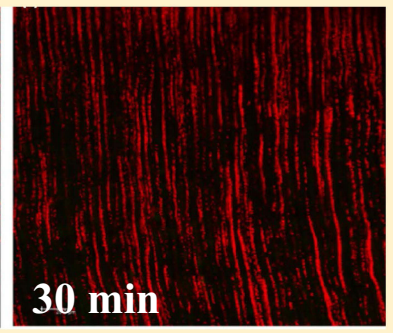

$2.5 \%$ sodium hypochlorite
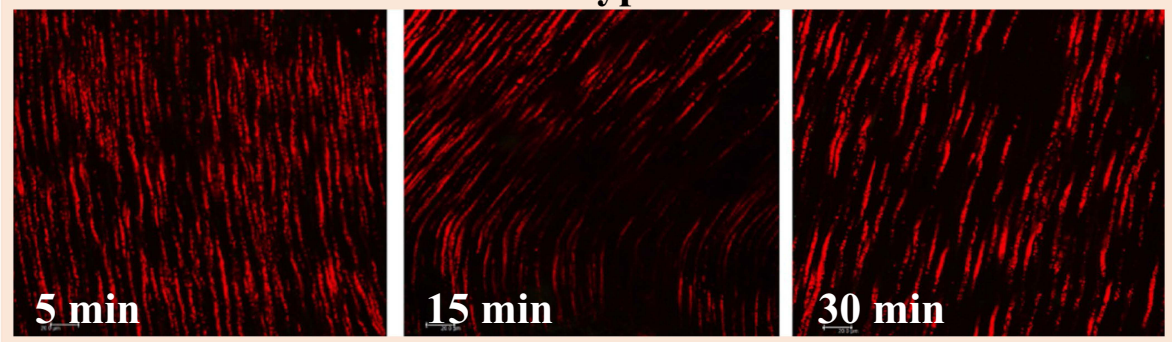

Figure 5 Application of root canal irrigation solution with AgNPs. (A) Representative images of Enterococcus faecalis biofilms after treatment with AgNPs for 5 , 15 and 30 min; (B). Representative images of Enterococcus faecalis inside the dentinal tubules after treatment with irrigating solutions: AgNPs, $2 \%$ chlorhexidine or $2.5 \%$ sodium hypochlorite for 5,15 and 30 min, respectively. Reproduced with permission from Rodrigues CT, de Andrade FB, de Vasconcelos LRSM, et al. Antibacterial properties of silver nanoparticles as a root canal irrigant against Enterococcus faecalis biofilm and infected dentinal tubules. Int Endod J. 20I8;5I (8):90I-9II . Copyright@20I8 International Endodontic Journal. Published by John Wiley \& Sons Ltd. ${ }^{91}$

polyvinyl alcohol-coated AgNPs and farnesol are more conducive to tissue repair and less cytotoxic than $\mathrm{NaClO} .{ }^{89}$ However, it is worth noting that AgNPs and SDF both have an effect on the bond strength of cemented fiber posts, which depends on the types of resin used. ${ }^{96}$

\section{Intracanal Medication and Gutta Percha Disinfectant}

The most common intracanal medication is calcium hydroxide paste, which releases hydroxyl ions to increase the $\mathrm{pH}$ and kill microbes in the canal. Afkhami et al mixed AgNPs (size $20 \mathrm{~nm}$ ) into calcium hydroxide paste, increasing their antimicrobial effect. ${ }^{88}$

Gutta percha is the most common root canal filling material and needs to be disinfected before use. Conventional detergent sodium hypochlorite can cause surface topography deterioration while a low concentration of AgNPs can avoid this problem. ${ }^{97}$ In addition, mineral trioxide aggregate (MTA) mixed with AgNPs and new experimental cement (CEM) significantly increased the antimicrobial activity, along with good biocompatibility and excellent mechanical strength. ${ }^{98-100}$

\section{Endodontic Sealers}

The requirements of ideal root canal sealants are: (1) excellent sealing properties during solidification; (2) sufficient solidification time to ensure the working time; (3) dimensional stability; (4) insoluble tissue fluid; (5) good adhesion to the tube wall; (6) suitable antimicrobial properties; and (7) biocompatibility. ${ }^{101}$ Enterococcus faecalis is the main microorganism associated with the failure of endodontic treatments. ${ }^{102,103}$ Utilizing antimicrobial agents, such as 
AgNPs, to mix with endodontic sealers may yield higher antimicrobial efficacy. Researchers have incorporated silver vanadate $\left(\mathrm{AgVO}_{3}\right)$ into various sealers, such as methacrylate resin-based sealers (Real Seal ${ }^{\circledR} /$ EndoRez $\left.^{\circledR}\right)$, zinc oxide eugenol (ZOE), epoxy resin-based sealers $\left(\mathrm{AH}\right.$ Plus ${ }^{\circledR}$ ) and calcium hydroxide-based sealers (Apexit ${ }^{\circledR}$ ). The addition of $\mathrm{AgBO}_{3}$ improves the antimicrobial performance of these commercial sealers against E. faecalis, P. aeruginosa and E. coli without reducing their mechanical properties. ${ }^{104-107}$ Baras et al reported a therapeutic root canal sealer including 5\% DMAHDM and $0.15 \%$ AgNPs to inhibit biofilmsand release silver ions into the complex and difficultto-reach root canal environment. ${ }^{107}$ The sealer inhibited endodontic biofilms and prevented recurrent endodontic infections via potent antibiofilm ability, and ensured sufficient sealer flow and sealing ability (Figure 6). Toxic products of sealers may hamper the periapical healing process by inhibiting the proliferative capability of the periradicular cell population. ${ }^{108}$ Although methacrylate resin-based sealers show the strongest potential to inhibit endodontic biofilms and prevent recurrent endodontic infections, they exhibit the greatest cytotoxicity and inflammatory potential against pulp cells compared to others. ${ }^{109}$ Marica et al prepared multiwalled carbon nanotubes (MWCNTs) coated with chlorhexidine (CHX) and colloidal AgNPs and incorporated them into commercial sealants, which improved the antimicrobial activity of the modified pulp sealants. ${ }^{110}$

\section{Applications of AgBMs in Periodontics}

Periodontitis is an inflammatory disease caused by multiple bacteria, resulting in the loss of alveolar. ${ }^{111}$ Traditional periodontal treatment involves subgingival scaling and root planning to remove plaque. Antibiotics are used in periodontal pockets to achieve good anti-infection results. ${ }^{112}$ AgNPs combined with antibiotics have a synergistic effect, which

A

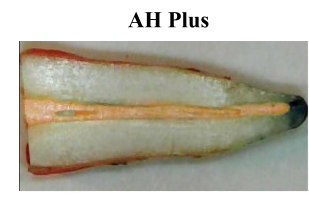

$\mathbf{B}$

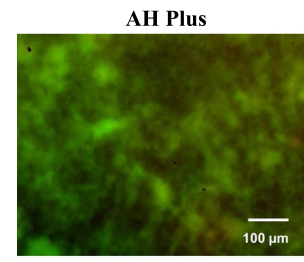

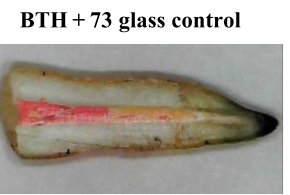
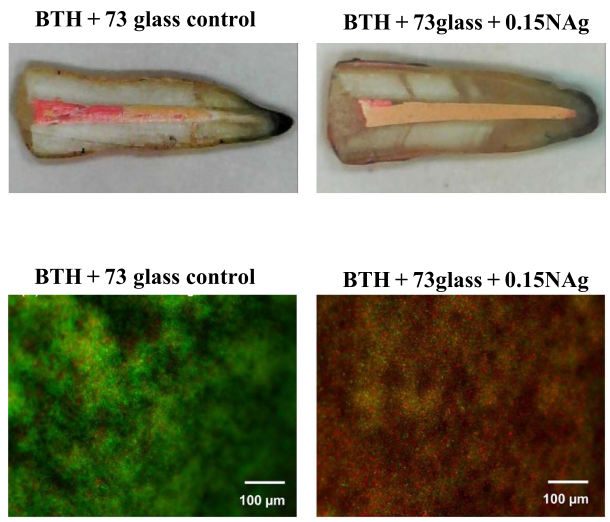
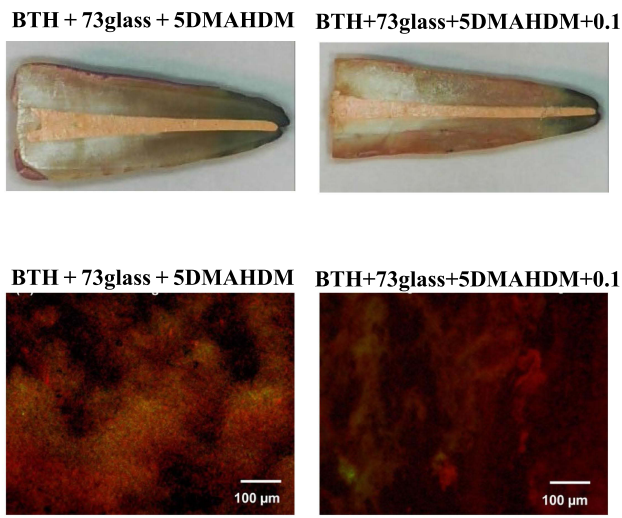
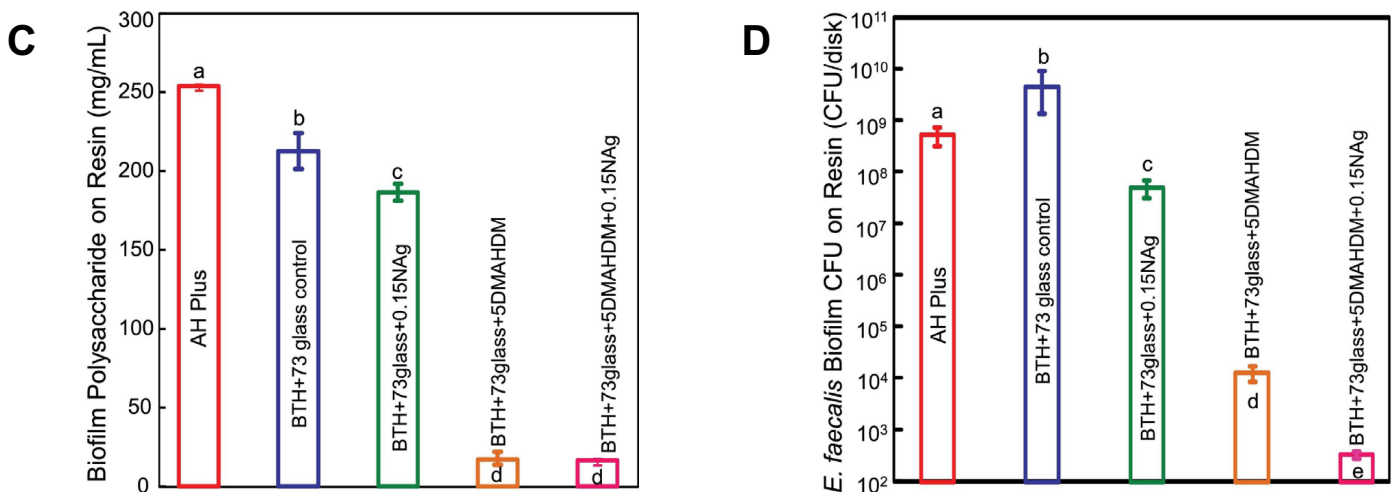

Figure 6 Application of AgBMs in Endodontic sealers. (A). Stereomicroscopic images showing apical dye penetration, and all experimental sealers showed similar sealing properties. (B). Live (green)/dead (red) images of 2-day biofilms adherent to resins. (C) Polysaccharide production by biofilms adherent to the sealer disks. (D) Colonyforming unit (CFU) counts of 2-day biofilms adherent to sealer disks. Reproduced with permission from Baras BH, Melo MAS, Sun J, et al. Novel endodontic sealer with dual strategies of dimethylaminohexadecyl methacrylate and nanoparticles of silver to inhibit root canal biofilms. Dent Mater. 20I9;35(8):III7-II29. Copyright@20I9 The Academy of Dental Materials. Published by Elsevier Inc. ${ }^{107}$ 
showed enhanced antimicrobial activity at concentrations far below the minimum inhibitory concentration (MIC) of individual antibiotics and AgNPs, with no cytotoxic effect toward mammalian cells. ${ }^{113}$

AgBMs have the potential to promote periodontal tissue regeneration. AgNPs could be utilized to enhance new collagen synthesis and neovascularization, resulting in gingival wound healing. ${ }^{114}$ Furthermore, a type of mesoporous silica-containing AgNPs was introduced by $\mathrm{Li}$ et al as a novel antimicrobial and osteogenic medicine that eliminates periodontal pathogenic microorganisms and stimulates bone tissue regeneration simultaneously (Figure 7). ${ }^{115}$

As a broad-spectrum antimicrobial material, silver can be used as an antibiotic additive to reduce the effects of bacterial resistance and can also modify scaffolds to induce alveolar bone regeneration. Conventional treatment could not regenerate alveolar bone lost in periodontitis. Guided tissue regeneration (GTR) is a surgical procedure to regain periodontal tissues by isolating periodontal defects with a membrane so that periodontal tissue will not be preempted by connective tissue. In this case, a silver-combined GTR membrane serves as an effective method to arrest bacterial colonization. ${ }^{116}$ Lee found that small concentrations of AgNPs can be used as a safe and reliable method when applied in GTR. ${ }^{117}$ Fibrin membranes rich in white blood cells and platelets can be used in a variety of regeneration treatments, and the addition of AgNPs improves their mechanical properties and antimicrobial activity. ${ }^{114}$ Electrospun chitosan/poly(ethylene oxide) membranes with different amounts of AgNPs were evaluated for antimicrobial properties and cytotoxicity in vitro and for tissue response. ${ }^{135}$ In addition, Qian et al developed a new type of silver-modified and collagen-coated electrospun polylactic acid-glycolic acid/polycaprolactone (PLGA/PCL) scaffold with improved antimicrobial and osteogenic properties. ${ }^{118}$

\section{Applications of AgBMs in Prosthodontics}

Prosthodontic materials require good mechanical properties to maintain shape during oral picking or chewing, so the impact on mechanical properties is a challenge before using AgBMs.

Denture stomatitis, mostly caused by Candida albicans biofilms, occurs in two- thirds of denture wearers. ${ }^{42,116}$ Polymethyl methacrylate (PMMA) is the most conventional material used as a denture base. However, it possesses poor antimicrobial properties. ${ }^{119}$ AgNPs and certain ionic AgNPs, such as $\mathrm{AgVO}_{3}$ NPs and $\mathrm{AgBr}$ NPs, could be incorporated into PMMA,

A

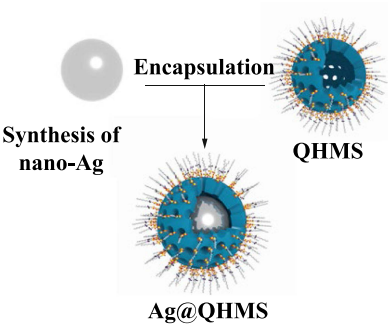

B
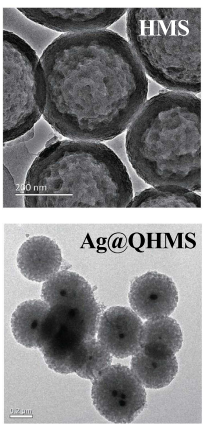

C
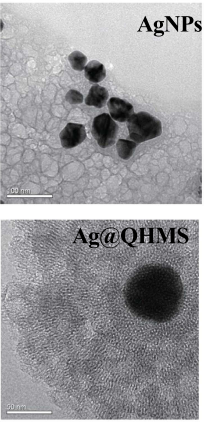
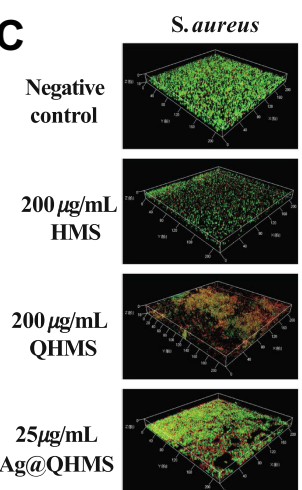

Ag@QHMS

$50 \mu \mathrm{g} / \mathrm{mL}$

Ag@QHMS

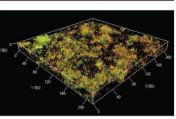

$100 \mu \mathrm{g} / \mathrm{mL}$ Ag@QHMS

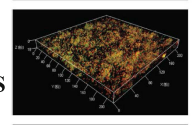

$200 \mu \mathrm{g} / \mathrm{mL}$ Ag@QHMS

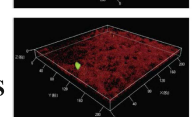

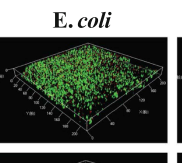
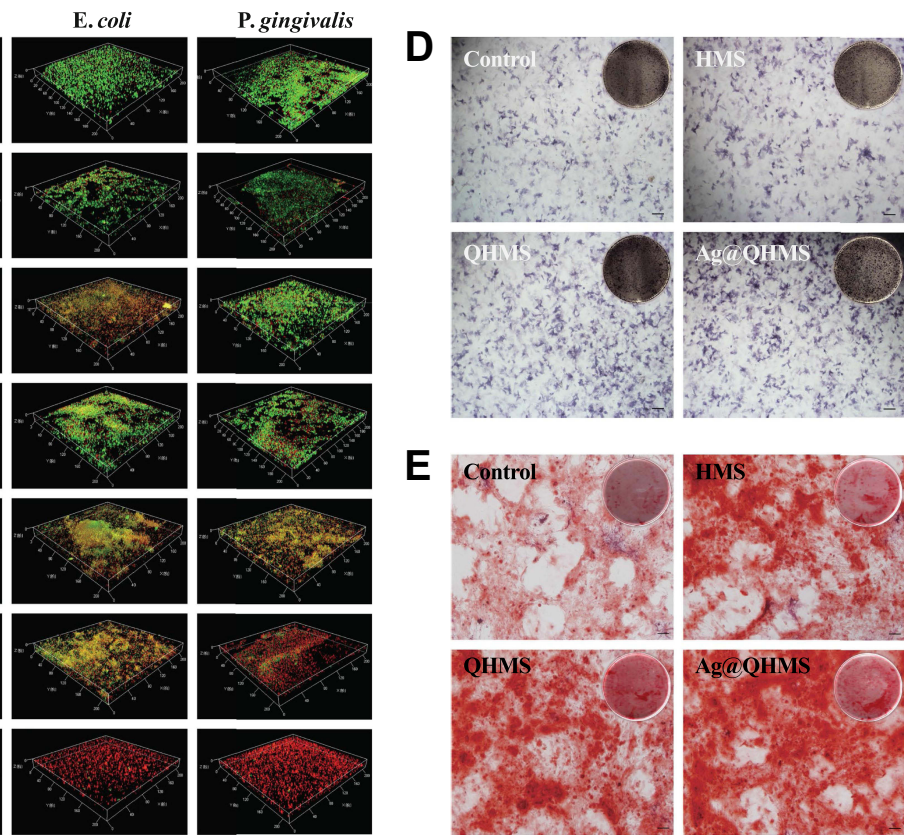

Figure 7 Applications of mesoporous silica containing AgNPs in periodontics. (A) Synthesis procedure of QAS-modified core-shell mesoporous silica containing Ag nanoparticles (Ag@QHMS). (B) The TEM images of Ag@QHMS. (C) Confocal laser scanning microscopy images of bacterial biofilms (S. aureus, E. coli, and P. gingivalis) after coculture with different nanoparticles through live/dead BacLight staining after 3 days. (D) Alkaline phosphatase (ALP) staining of BMSCs after I week. (E) Alizarin Red staining after 2 weeks. Reproduced with permission from Li D, Qiu Y, Zhang S, Zhang M, Chen Z, Chen J. A Multifunctional Antibacterial and Osteogenic Nanomedicine: QAS-Modified Core-Shell Mesoporous Silica Containing Ag Nanoparticles. Biomed Res Int. 2020:4567049. Copyright (C) 2020 Dexiong Li et al. This is an open access article distributed under the Creative Commons Attribution License. ${ }^{115}$ 
improving the antimicrobial properties and mechanical strength of the denture base. ${ }^{15,120-125}$ Additionally, AgBMs can also be loaded and integrated into a resin base, such as silver sulfadiazine-loaded mesoporous silica nanocarriers and AgNP-loaded cellulose nanocrystals. ${ }^{125}$ PMMA with cellulose nanocrystal-AgNPs of $0.1 \mathrm{wt} \%$ possessed the most desirable mechanical properties and can be used as a functional dental restoration material (Figure 8). ${ }^{126}$

Swathy et al reported that the antimicrobial effects of silver ions are weakened because they will bind to chloride in a saliva solution. ${ }^{127}$ To overcome this dilemma, Yoshihara et al loaded acid-silver clathrate (Met or His-Ag) into montmorillonite, a porous structure capable of controlled release, which showed a higher $\mathrm{Ag}^{+}$concentration in the presence of $\mathrm{Cl}^{-} .{ }^{128} \mathrm{Similarly}$, the mouthguard (MG) used to protect athletes' teeth requires modification of antimicrobial materials because the porous structure is

A

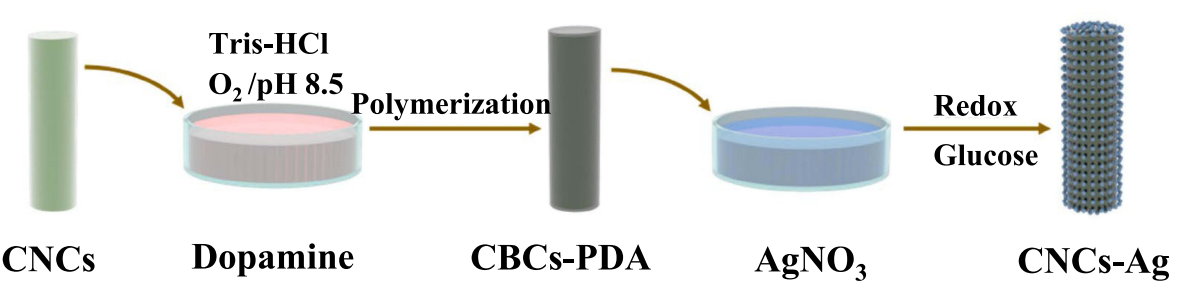

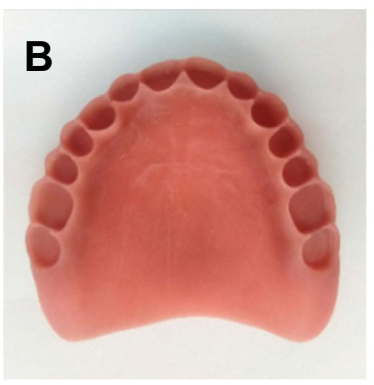

D

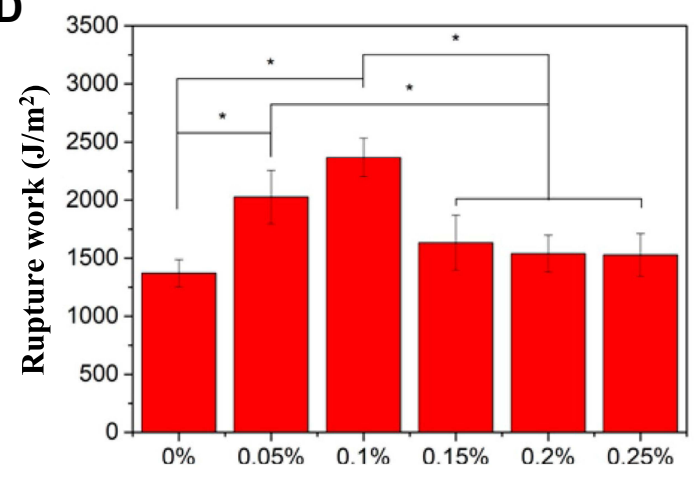

Content

$\mathbf{F}$

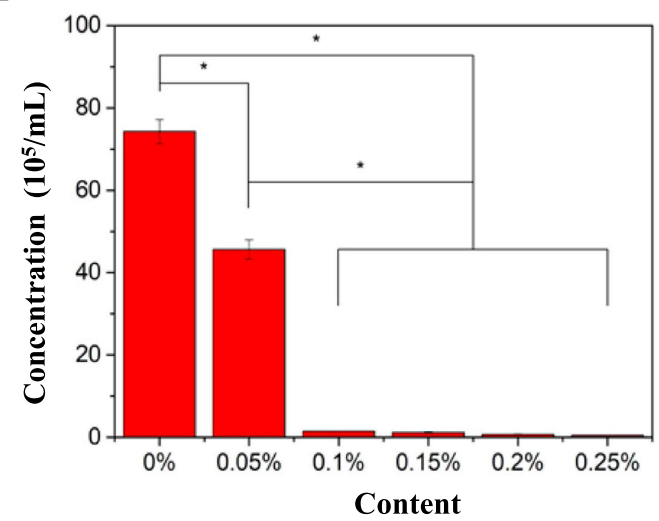

Figure 8 3D-Printable Reinforced Composite Resin-Based PMMA Modified with AgNPs. (A) Synthetic route of the nanocrystalline cellulose-silver (CNCs-Ag) composite. (B) 3D printed denture base using composite PMMA containing I wt\% CNCs-Ag. Flexural properties and impact resistance of PMMA resin containing CNCs-Ag with different mass concentrations: (C) Flexural strength and (D) rupture work. Antibacterial activity of PMMA resin containing CNCs-Ag with different mass concentrations. (E) S. aureus; (F) E. coli. *p < 0.05 was considered statistically significant. Reproduced with permission from Chen S, Yang J, Jia YG, Lu B, Ren L. A Study of 3D-Printable Reinforced Composite Resin: PMMA Modified with Silver Nanoparticles Loaded Cellulose Nanocrystal. Materials (Basel). 20I8; I ( I2):2444. Copyright@20I8 by the Authors. Licensee MDPI, Basel, Switzerland. This article is an open access article distributed under the terms and conditions of the Creative Commons Attribution (CC BY) license (http://creativecommons.org/licenses/by/4.0/). ${ }^{126}$ 
a reservoir for bacterial growth. MGcontaining silver can significantly improve its antimicrobial activity without affecting its mechanical properties of absorption kinetic energy. ${ }^{129}$

Oral impression is a traditional method to reproduce dentition shape in vitro, which requires antimicrobial disinfection during transportation. Conventional sprays and immersion disinfection of irreversible colloidal impression materials can cause size changes, while the addition of AgNPs can produce excellent antimicrobial activity without adversely affecting its properties. ${ }^{130}$ The fracture toughness and antimicrobial properties of dental crowns are important in prosthodontics. It was confirmed that AgNPs significantly improved the Young's modulus and fracture toughness of dental porcelain and reduced the risk of fracture of porcelain restorations. ${ }^{131,132}$

\section{Applications of AgBMs in Implant Dentistry}

Dental implant surgery is performed in a contaminated oral cavity, in which case, bacterial invasion (S. mutans, P. gingivalis) is inevitable. Polymicrobial biofilms containing Candida species-which may compromise periimplantitis - causes the loss of supporting bone and the failure of implant surgery. ${ }^{133}$

The antibacterial performance of the implant surface can be improved by coating modification. ${ }^{134}$ To overcome this challenge, silver-containing implant coatings have attracted increasing attention because they effectively retard microbial growth. ${ }^{135,136}$ The presence of AgNPs on titanium provides antimicrobial activity related to the bacteria involved in periimplantitis. ${ }^{137}$ However, Ag biodegradation may limit its antibacterial function. Considering that early-stage (6 hours after surgery) infection is the crucial factor of implantation failure, controlled release within the postsurgery period is the key resolution. Long-term antimicrobial effects can be achieved by various coating methods, including titanium dioxide nanotubes, polydopamine coatings, microarc oxidation crafts, calcium-treated Ti metal, and poly-1-lysine/sodium alginate coatings. ${ }^{136,138-141}$ AgNPs modification can not only significantly enhance the antimicrobial activity of titanium implants

\section{A}
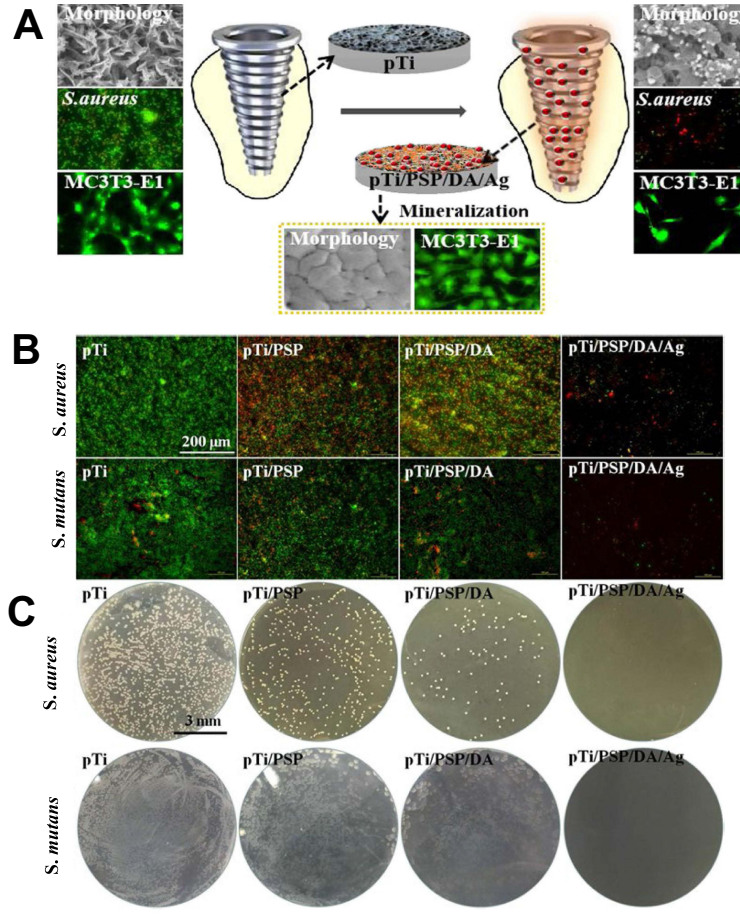

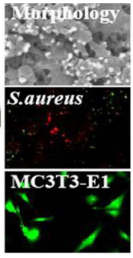

D

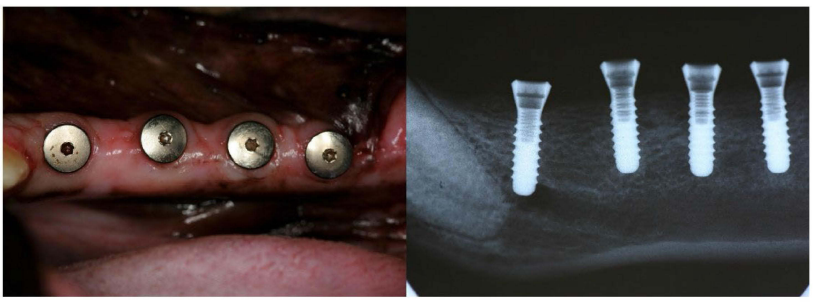

E

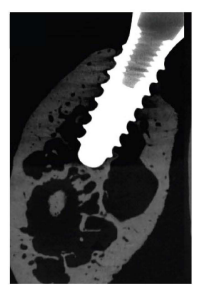

SLA

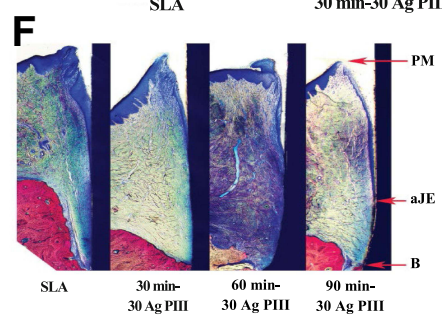

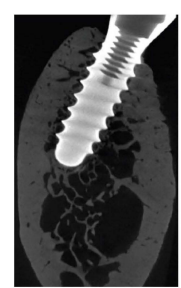

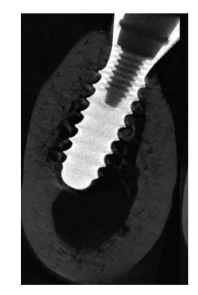

$\mathbf{G}$

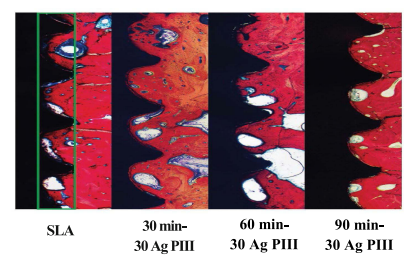

Figure 9 AgBM-modified implants promote antimicrobial property and bone formation. (A) Schematic illustration of antibacterial surface modification of Ti implants for preventing implant-associated infection. (B) Fluorescence micrographs of S. aureus and S. mutans, and (C) bacterial colony-forming units on different implant surfaces after incubation for 24 h. (A-C) Reproduced with permission from Guo C, Cu W, Wang X, et al. Poly-l-lysine/sodium alginate coating loading nanosilver for improving the antibacterial effect and inducing mineralization of dental implants. ACS Omega. 2020;5(I8):10562-1057I. Copyright@2020 American Chemical Society. ${ }^{141}$ (D) Clinical photograph and the corresponding radiograph at 12 weeks postsurgery in labrador dogs. (E) Radiography and micro-CT evaluation of the bone tissue around dental implants. (F) Histological images demonstrating the landmarks that were used for the assessment of linear distance for the soft tissue. (G) Histological sections stained with van Gieson's picro fuchsin. (D-G) Reproduced with permission from Qiao S, Cao H, Zhao X, et al. Ag-plasma modification enhances bone apposition around titanium dental implants: an animal study in Labrador dogs. Int J Nanomedicine. 2015;10:653-64. Copyright@20I5 Dove Medical Press Limited. ${ }^{142}$ 
but also promote osteogenesis around titanium dental implants (Figure 9). ${ }^{142}$ Contact killing of immobilized AgNPs is another method to maintain the antimicrobial effect, offering good defense against $F$. nucleatum and $S$. aureus, with no apparent toxic influence on rat bone marrow mesenchymal stem cells. ${ }^{32}$ Immobilized AgNPs were almost confined to cell surfaces compared to free AgNPs, which were distributed throughout cells. ${ }^{143}$ Sol-gel and chloride-induced selfassembly and electrochemical deposition are the main methods for making silver coatings on titanium surfaces. ${ }^{32,144}$ The photocatalysis-mediated antimicrobial activity of AgNPs may offer a promising solution for the improvement of the antimicrobial properties of dental implants. ${ }^{145}$ Furthermore, silver-coated abutments could prevent leakage of microorganisms via the implant-abutment interfaces. The attachment and proliferation of Candida albicans on implants could be reduced by AgNPs. ${ }^{146}$ Interestingly, silver-induced electrochemical effects could promote antimicrobial and osteogenic effects simultaneously. Zhang et al first created a nanoscale galvanic redox system between AgNPs and $316 \mathrm{~L}$ stainless steel alloy, which promoted peri-implant osteogenesis and antimicrobial activity. ${ }^{147}$

In addition to titanium, silver coatings on other materials also show excellent antimicrobial ability and biocompatibility. Polyether ether ketone (PEEK), a thermoplastic polymer closer to the elastic modulus of the bone cortex than titanium, is mainly used in the manufacture of temporary abutments, implant abutments, and healing caps. PEEK coated with AgNPs has been proven to exhibit significantly improved antimicrobial properties and biocompatibility. ${ }^{148}$ In regard to implantsupported fixed partial dentures, the contact killing effect of silver is utilized to complement the weakened $\mathrm{Ag}^{+}$. For instance, AgNP-coated yttria-stabilized zirconia controls dental caries and periodontal disease without releasing $\mathrm{Ag}^{+} \cdot 149$

Similar to GTR periodontal treatment, guided bone generation (GBR) aims at regenerating alveolar bone by isolating the defect with an occlusive membrane. AgNP-coated collagen membranes showed antibacterial effects against Staphylococcus aureus and Pseudomonas aeruginosa. It also reduces the release of inflammatory cytokines including IL-6 and TNF- $\alpha$. Furthermore, AgNP-coated collagen membranes were able to induce osteogenic differentiation of mesenchymal stem cells that guide bone regeneration. ${ }^{150}$

\section{AgBMs in Oral and Maxillofacial Surgery}

In the area of oral and maxillofacial surgery, $\mathrm{AgBMs}$ are employed in wound dressings and sutures due to their biocompatibility, reduction of tissue reaction and sterilization. ${ }^{151}$

Colloidal silver gelatin sponges are generally utilized in tooth extraction wounds, speeding up the bone healing process in the prevention of dry sockets. ${ }^{152}$ Oral infectious diseases may lead to bone loss, and the rise of multidrugresistant bacteria limits the use of antibiotics. Methicillin-resistant Staphylococcus aureus (MRSA) is one of the most common pathogens of oral infection. Dong et al reported that gelatin sponges containing colloidal silver can effectively reduce infections caused by MRSA in skull defects (Figure 10). ${ }^{153}$ Additionally, AgBMs are widely employed as dressings for burn wounds. For example, silver sulfadiazine (AgSD) has been applied as a topical drug in the treatment of burn wounds since the 1960s, while its effectiveness was questioned by a Cochrane database systematic review. ${ }^{16,154}$ With the advancement of new technologies, AgSD shows strong sterilization in combined use with other dressing materials or scaffolding materials, such as microsponges and silk fibroin. ${ }^{155}$

Silver wires were used as wound sutures early in $1800 .{ }^{16}$ In recent years, several deposition processes have been attempted to make AgNP-coated sutures a novel approach against surgical infections. ${ }^{156}$ These AgNP-coated sutures exhibit strong bactericidal effects on common wound pathogens, such as S. aureus, E. coli, K. pneumoniae and P. aeruginosa, with no influence on the viability of human keratinocyte cells. ${ }^{157-159}$

Interestingly, the antibacterial properties of AgNPs can be used as a tool to regulate the microbiota to interfere with the host's immune system. Zheng et al discovered that in oral squamous cell carcinoma (OSCC), AgNPs could regulate the oral microbiota and make $P$. anaerobius the dominant bacteria, which induces an anticancer immune response and inhibits tumor growth. ${ }^{160}$ This study provides an enlightening research direction for antibacterial biomaterials in which antimicrobial biomaterials could be utilized in host microbiota reactions.

\section{The Future Prospective}

The widespread presence of pathogenic bacteria has posed threat to healthcare, especially in the dental field. Plaque biofilms of oral cavity are complex community which can causes infection by protecting pathogenic microorganisms 

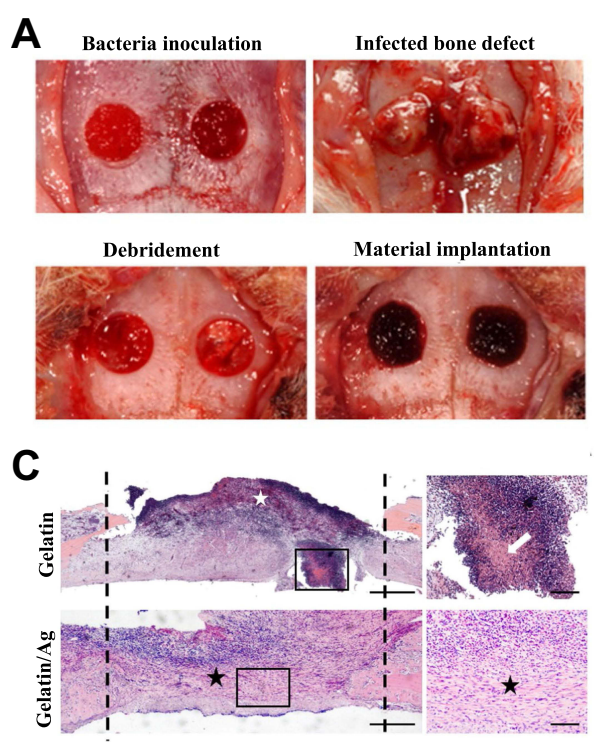
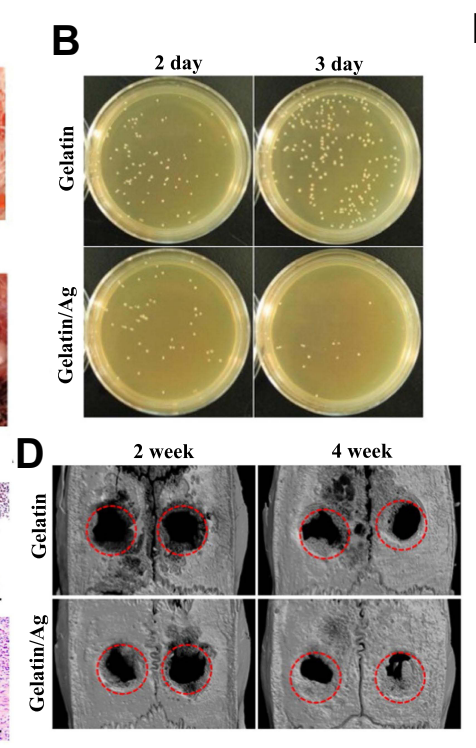

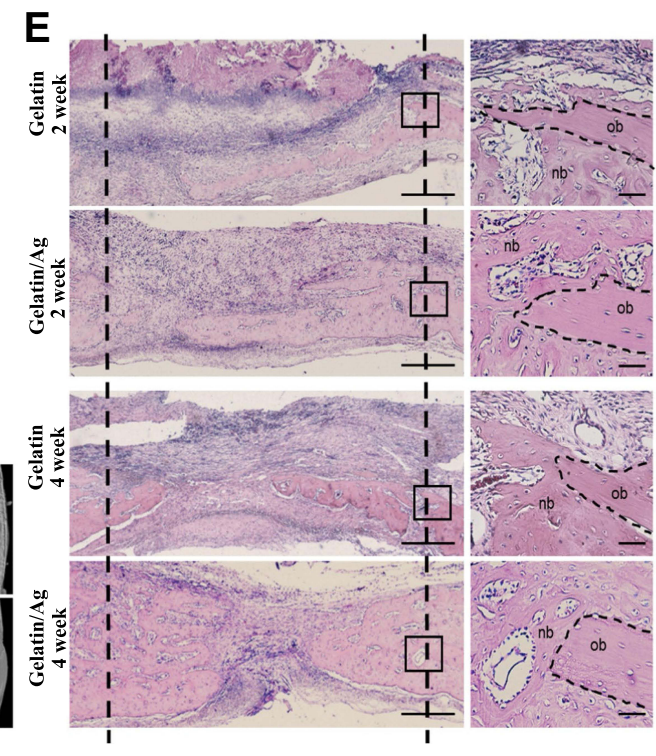

Figure 10 Gelatin sponge with colloidal silver (gelatin/Ag) promoted bone healing in infected cranial defects. (A) Creation of infected cranium defects and macroscopic appearance of the defects at main time points. (B) Antibacterial effect of Gelatin/Ag after debridement. (C) Representative images of HE-stained sections at 2 days after debridement. (D) Three-dimensional reconstructions of the cranium at 2 and 4 weeks. (E) Representative images of HE-stained sections of defects at 2 and 4 weeks. Reproduced with permission from Dong Y, Liu W, Lei Y, et al. Effect of gelatin sponge with colloidal silver on bone healing in infected cranial defects. Mater Sci Eng C Mater Biol Appl. 2017;70(Pt I):37I-377. Copyright@2016 Published by Elsevier B.V. ${ }^{153}$

from external drug agents and escaping host defense mechanisms. Thus, plaque biofilm is a major factor resulting in caries, periodontitis, periimplantitis, and other dental diseases. AgBMs are promising in antibacterial therapies owe to their unique physicochemical properties. For example, the nanoparticle form of AgBMs have ultra-small sizes, large surface-area-to-mass ratios and increased chemical reactivity, and the large surface area of AgNPs with high charge density enables them to interact with the negatively-charged surface of bacterial cells to a greater extent resulting in enhanced antimicrobial activity. In addition, AgBMs were found to exhibit superior antimicrobial properties in the oral cavity, when combined with polymers or coated onto dental material surfaces. Thus, AgBMs enhance the antimicrobial properties of dental materials and are widely used in dental caries control, root canal therapy, prostheses, periodontal treatment, dental implants or maxillofacial surgery.

AgBMs have unique antibacterial advantages base on the variety of mechanisms. The major antimicrobial mechanism of AgBMs is now recognized as the release of silver ions. The combination of silver ions and thiol groups causes ribosome and respiratory chain dysfunction, which determines the survival of cells. The exhaustion of thiol groups in turn leads to the overproduction of ROS, destroying proteins, DNA and lipids. Moreover, AgBMs can suppress bacterial metabolism, accumulate chemicals that damage cellular components, or damage the integrity of the cell membrane. AgBMs can also be employed in PDT as promising photosensitizers for promoting and prolonging antibacterial effects. Therefore, compared with traditional antibiotics, AgBMs could improve the antibacterial effect while reducing the drug resistance.

Several disadvantages limit the clinical application of AgBMs. First, the antimicrobial effectiveness of AgBMs is limited in the oral environment due to silver resistance of bacteria. Chloride ions extensively exist in saliva and gingival crevicular fluid, leading to the precipitation reaction with silver ions. Bacteria can weaken the antibacterial properties of AgBMs through efflux ion pumps, flagellin and other means. Thus, the optimization of controlled-release mechanism and contact-killing property are potential strategies to extend the valid time of AgBMs. Combined utilization with other antibacterial biomaterials or molecules may have a better effect. For instance, the complementary use of flagellin production inhibitors also offers viable measures against gram-negative bacteria. Second, the biosafety of many AgBMs remains controversial, particularly burgeoning AgNPs. Thus, as dental materials or ingredients of topical drugs, AgBM carriers need to be designed to reduce systemic toxicity. Multiple influential toxicity factors of AgNPs 
need to be considered, such as nanoparticle size, shape, surface charge, dosage, oxidation state, agglomeration condition, and cell type. Third, AgBMs raise concern for oral aesthetics. The precipitation of some silver byproducts, such as silver amalgam and SDF, could stain dental or soft issue black. Therefore, aesthetic considerations should be taken before AgBMs are used in the oral environment. Overcoming the dyeing disadvantage of AgBMs is an important factor to promote their application in the clinic.

AgBMs have been widely researched and applied in cariostatic treatment, coatings of various dental appliances, periodontal treatment, and wound dressings because of their antimicrobial properties. Based on predictable clinical effects, $\mathrm{AgBMs}$ have broad development prospects in the future. AgBMs could even interfere in the immune system due to the hostmicrobiota reaction. Interdisciplinary antibacterial and immunomodulation may be the future development direction of AgBMs. With the advancement of research on engineering technology and composite materials, more applications of AgBMs will be developed. Safer and more efficient antimicrobial AgBMs in dentistry are expected to be obtained soon.

\section{Acknowledgments}

The authors would like to thank the original authors of the figures and all references for their significant research contributing to this manuscript.

\section{Author Contributions}

All authors made a significant contribution to the work reported, whether that is in the conception, study design, execution, acquisition of data, analysis and interpretation, or in all these areas; took part in drafting, revising or critically reviewing the article; gave final approval of the version to be published; have agreed on the journal to which the article has been submitted; and agree to be accountable for all aspects of the work.

\section{Funding}

This review was funded by the National Natural Sciences Foundation of China (81371680), and Jiangsu Provincial Medical Talent (ZDRCC2016016), Key Project of Research and Development Plan of Jiangsu Province (BE2020629), and Development of Science and Technology of Nanjing (YKK19094).

\section{Disclosure}

The authors declare no conflicts of interest.

\section{References}

1. Høiby N, Bjarnsholt T, Givskov M, et al. Antibiotic resistance of bacterial biofilms. Int J Antimicrob Agents. 2010;35(4):322-332. doi:10.1016/ j.ijantimicag.2009.12.011

2. Song W, Ge SA-O. Application of antimicrobial nanoparticles in dentistry. Molecules. 2019;24(6):1033. doi:10.3390/molecules24061033

3. Halkai KR, Mudda JA, Shivanna V, Rathod V, Halkai RS. Biosynthesis, characterization and antibacterial efficacy of silver nanoparticles derived from endophytic fungi against P. gingivalis. J Clin Diagn Res. 2017;11(9):Zc92-zc96.doi: 10.7860/JCDR/2017/29434.10681

4. Lara HH, Garza-Treviño EN, Ixtepan-Turrent L, et al. Silver nanoparticles are broad-spectrum bactericidal and virucidal compounds. J Nanobiotechnology. 2011;9(1):30. doi:10.1186/1477-3155-9-30

5. Kesharwani P, Gorain B, Low SY, et al. Nanotechnology based approaches for anti-diabetic drugs delivery. Diabetes Res Clin Pract. 2018;136:52-77. doi:10.1016/j.diabres.2017.11.018

6. Li X, Lenhart JJ, Walker HW. Aggregation kinetics and dissolution of coated silver nanoparticles. Langmuir. 2012;28(2):1095-1104. doi:10.1021/la202328n

7. Morozova OV, Volosneva ON, Levchenko OA, Barinov NA, Klinov DV. Protein corona on gold and silver nanoparticles. In: Materials Science Forum. Trans Tech Publ; 2018. doi:10.4028/www.scientific.net/MSF.936.42

8. Biswas A, Bayer IS, Biris AS, et al. Advances in top-down and bottom-up surface nanofabrication: techniques, applications \& future prospects. Adv Colloid Interface Sci. 2012;170(1-2):2-27. doi:10.1016/j.cis.2011.11.001

9. García-Contreras R, Argueta-Figueroa L, Mejía-Rubalcava C, et al. Perspectives for the use of silver nanoparticles in dental practice. Int Dent J. 2011;61(6):297-301. doi:10.1111/j.1875-595X.2011.00072.x

10. Rai MK, Deshmukh SD, Ingle AP, et al. Silver nanoparticles: the powerful nanoweapon against multidrug-resistant bacteria. J Appl Microbiol. 2012;112(5):841-852. doi:10.1111/j.1365-2672.2012.05253.x

11. Verma S, Chevvuri R, Sharma H. Nanotechnology in dentistry: unleashing the hidden gems. J Indian Soc Periodontol. 2018;22(3):196-200. doi:10.4103/jisp.jisp_35_18

12. Zafar MS, Khurshid Z, Najeeb S, Zohaib S, Rehman IU. Therapeutic applications of nanotechnology in dentistry. Nanostructures for Oral Medicine. 2017:833-862. 
13. Khurshid Z, Zafar M, Qasim S, et al. Advances in nanotechnology for restorative dentistry. Materials (Basel). 2015;8(2):717-731. doi:10.3390/ ma8020717

14. Zafar MS, Alnazzawi AA, Alrahabi M, et al. 18 - Nanotechnology and nanomaterials in dentistry - ScienceDirect. . Advanced Dental Biomaterials. Woodhead Publishing; 2019:477-505.doi: 10.1016/B978-0-08-102476-8.00018-9

15. Kreve S, Oliveira $\mathrm{VC}$, Bachmann $\mathrm{L}$, et al. Influence of $\mathrm{AgVO}(3)$ incorporation on antimicrobial properties, hardness, roughness and adhesion of a soft denture liner. Sci Rep. 2019;9(1):11889. doi:10.1038/s41598-019-48228-8

16. Medici S, Peana M, Nurchi VM, et al. Medical uses of silver: history, myths, and scientific evidence. J Med Chem. 2019;62(13):5923-5943. doi:10.1021/acs.jmedchem.8b01439

17. Khan ST, Musarrat J, Al-Khedhairy AA. Countering drug resistance, infectious diseases, and sepsis using metal and metal oxides nanoparticles: current status. Colloids Surf B Biointerfaces. 2016;146:70-83. doi:10.1016/j.colsurfb.2016.05.046

18. Shanmugasundaram T, Radhakrishnan M, Gopikrishnan V, Kadirvelu K, Balagurunathan R. In vitro antimicrobial and in vivo wound healing effect of actinobacterially synthesised nanoparticles of silver, gold and their alloy. RSC Adv. 2017;7(81):51729-51743. doi:10.1039/c7ra08483h

19. Lee YJ, Kim J, Oh J, et al. Ion-release kinetics and ecotoxicity effects of silver nanoparticles. Environ Toxicol Chem. 2012;31(1):155-159. doi:10.1002/etc. 717

20. Yamanaka M, Hara K, Kudo J. Bactericidal actions of a silver ion solution on Escherichia coli, studied by energy-filtering transmission electron microscopy and proteomic analysis. Appl Environ Microbiol. 2005;71(11):7589-7593. doi:10.1128/AEM.71.11.7589-7593.2005

21. Gordon O, Vig Slenters T, Brunetto PS, et al. Silver coordination polymers for prevention of implant infection: thiol interaction, impact on respiratory chain enzymes, and hydroxyl radical induction. Antimicrob Agents Chemother. 2010;54(10):4208-4218. doi:10.1128/AAC.01830-09

22. Oves M, Aslam M, Rauf MA, et al. Antimicrobial and anticancer activities of silver nanoparticles synthesized from the root hair extract of Phoenix dactylifera. Mater Sci Eng C Mater Biol Appl. 2018;89:429-443. doi:10.1016/j.msec.2018.03.035

23. Samuel MS, Jose S, Selvarajan E, et al. Biosynthesized silver nanoparticles using Bacillus amyloliquefaciens; Application for cytotoxicity effect on A549 cell line and photocatalytic degradation of p-nitrophenol. J Photochem Photobiol B. 2020;202:111642. doi:10.1016/j. jphotobiol.2019.111642

24. Zhao X, Zhou L, Riaz Rajoka MS, et al. Fungal silver nanoparticles: synthesis, application and challenges. Crit Rev Biotechnol. 2018;38 (6):817-835. doi:10.1080/07388551.2017.1414141

25. Durán N, Nakazato G, Seabra AB. Antimicrobial activity of biogenic silver nanoparticles, and silver chloride nanoparticles: an overview and comments. Appl Microbiol Biotechnol. 2016;100(15):6555-6570. doi:10.1007/s00253-016-7657-7

26. Wang Y, Yang Y, Shi Y, et al. Antibiotic-free antibacterial strategies enabled by nanomaterials: progress and perspectives. Adv Mater. 2020;32 (18):e1904106. doi:10.1002/adma.201904106

27. Park HJ, Kim JY, Kim J, et al. Silver-ion-mediated reactive oxygen species generation affecting bactericidal activity. Water Res. 2009;43 (4):1027-1032. doi:10.1016/j.watres.2008.12.002

28. Shitomi K, Miyaji H, Miyata S, et al. Photodynamic inactivation of oral bacteria with silver nanoclusters/rose bengal nanocomposite. Photodiagnosis Photodyn Ther. 2020;30:101647. doi:10.1016/j.pdpdt.2019.101647

29. Morozova OV. Silver nanostructures: limited sensitivity of detection, toxicity and anti-inflammation effects. Int J Mol Sci. 2021;22(18):9928. doi:10.3390/ijms22189928

30. Ivanova EP, Hasan J, Webb HK, et al. Bactericidal activity of black silicon. Nat Commun. 2013;4(1):2838. doi:10.1038/ncomms3838

31. Lu X, Feng X, Werber JR, et al. Enhanced antibacterial activity through the controlled alignment of graphene oxide nanosheets. Proc Natl Acad Sci U S A. 2017;114(46):E9793-e9801. doi:10.1073/pnas.1710996114

32. Lu X, Zhang B, Wang Y, et al. Nano-Ag-loaded hydroxyapatite coatings on titanium surfaces by electrochemical deposition. $J R$ Soc Interface. 2011;8(57):529-539. doi:10.1098/rsif.2010.0366

33. Slawson RM, Van Dyke MI, Lee H, et al. Germanium and silver resistance, accumulation, and toxicity in microorganisms. Plasmid. 1992;27 (1):72-79. doi:10.1016/0147-619X(92)90008-X

34. Silver S. Bacterial silver resistance: molecular biology and uses and misuses of silver compounds. FEMS Microbiol Rev. 2003;27(23):341-353. doi:10.1016/S0168-6445(03)00047-0

35. Panáček A, Kvítek L, Smékalová M, et al. Bacterial resistance to silver nanoparticles and how to overcome it. Nat Nanotechnol. 2018;13 (1):65-71. doi:10.1038/s41565-017-0013-y

36. Mulley G, Jenkins AT, Waterfield NR, Marr AC. Inactivation of the antibacterial and cytotoxic properties of silver ions by biologically relevant compounds. PLoS One. 2014;9(4):e94409. doi:10.1371/journal.pone.0094409

37. Gupta A, Matsui K, Lo J-F, et al. Molecular basis for resistance to silver cations in Salmonella. Nat Med. 1999;5(2):183-188. doi:10.1038/5545

38. Vilarrasa J, Delgado LM, Galofré M, et al. In vitro evaluation of a multispecies oral biofilm over antibacterial coated titanium surfaces. $J$ Mater Sci Mater Med. 2018;29(11):164. doi:10.1007/s10856-018-6168-8

39. Joshi AS, Singh P, Mijakovic I. Interactions of gold and silver nanoparticles with bacterial biofilms: molecular interactions behind inhibition and resistance. Int J Mol Sci. 2020;21(20):7658. doi:10.3390/ijms21207658

40. Agnihotri R, Gaur SA-O, Albin S. Nanometals in dentistry: applications and toxicological implications-a systematic review. Biol Trace Elem Res. 2020;197(1):70-88. doi:10.1007/s12011-019-01986-y

41. Cooper CF, Jolly WC. Ecological effects of silver iodide and other weather modification agents: a review. Water Resour Res. 1970;6(1):88-98. doi:10.1029/WR006i001p00088

42. Liao C, Li Y, Tjong SC. Bactericidal and cytotoxic properties of silver nanoparticles. Int J Mol Sci. 2019;20(2):449. doi:10.3390/ijms20020449

43. Hadrup N, Sharma AK, Loeschner K. Toxicity of silver ions, metallic silver, and silver nanoparticle materials after in vivo dermal and mucosal surface exposure: a review. Regul Toxicol Pharmacol. 2018;98:257-267. doi:10.1016/j.yrtph.2018.08.007

44. Miyayama T, Arai Y, Suzuki N, et al. Mitochondrial electron transport is inhibited by disappearance of metallothionein in human bronchial epithelial cells following exposure to silver nitrate. Toxicology. 2013;305:20-29. doi:10.1016/j.tox.2013.01.004

45. Piao MJ, Kang KA, Lee IK, et al. Silver nanoparticles induce oxidative cell damage in human liver cells through inhibition of reduced glutathione and induction of mitochondria-involved apoptosis. Toxicol Lett. 2011;201(1):92-100. doi:10.1016/j.toxlet.2010.12.010

46. Teodoro JS, Simões AM, Duarte FV, et al. Assessment of the toxicity of silver nanoparticles in vitro: a mitochondrial perspective. Toxicol In Vitro. 2011;25(3):664-670. doi:10.1016/j.tiv.2011.01.004 
47. Recordati C, De Maglie M, Cella C, et al. Repeated oral administration of low doses of silver in mice: tissue distribution and effects on central nervous system. Part Fibre Toxicol. 2021;18(1):23. doi:10.1186/s12989-021-00418-x

48. Browning JC, Levy ML. Argyria attributed to silvadene application in a patient with dystrophic epidermolysis bullosa. Dermatol Online J. 2008;14(4):9. doi:10.5070/D34W81J7SM

49. Van Landuyt K, Hellack B, Van Meerbeek B, et al. Nanoparticle release from dental composites. Acta Biomater. 2014;10(1):365-374 doi:10.1016/j.actbio.2013.09.044

50. Wang W, Li T, Luo X, et al. Cytotoxic effects of dental prosthesis grinding dust on RAW264.7 cells. Sci Rep. 2020;10(1):14364. doi:10.1038/ s41598-020-71485-x

51. Hadrup N, Sharma AK, Loeschner K, et al. Pulmonary toxicity of silver vapours, nanoparticles and fine dusts: a review. Regul Toxicol Pharmacol. 2020;115:104690. doi:10.1016/j.yrtph.2020.104690

52. Iwasaki Y, Saito Y, Nakano Y, et al. Chromatographic and mass spectrometric analysis of glutathione in biological samples. J Chromatogr B Analyt Technol Biomed Life Sci. 2009;877(28):3309-3317. doi:10.1016/j.jchromb.2009.07.001

53. Nedeljkovic I, De Munck J, Vanloy A, et al. Secondary caries: prevalence, characteristics, and approach. Clin Oral Investig. 2020;24 (2):683-691. doi:10.1007/s00784-019-02894-0

54. Eslamian L, Borzabadi-Farahani A, Karimi S, et al. Evaluation of the Shear bond strength and antibacterial activity of orthodontic adhesive containing silver nanoparticle, an in-vitro study. Nanomaterials (Basel). 2020;10(8):1466. doi:10.3390/nano10081466

55. Yin IX, Zhao IS, Mei ML, et al. Use of silver nanomaterials for caries prevention: a concise review. Int J Nanomedicine. 2020;15:3181-3191 doi:10.2147/IJN.S253833

56. Seifo N, Cassie H, Radford JR, et al. Silver diamine fluoride for managing carious lesions: an umbrella review. BMC Oral Health. 2019;19 (1):145. doi:10.1186/s12903-019-0830-5

57. Şuhani MF, Băciuţ G, Băciuţ M, et al. Current perspectives regarding the application and incorporation of silver nanoparticles into dental biomaterials. Clujul Med. 2018;91(3):274-279. doi:10.15386/cjmed-935

58. Peng JJ, Botelho MG, Matinlinna JP. Silver compounds used in dentistry for caries management: a review. J Dent. 2012;40(7):531-541. doi:10.1016/j.jdent.2012.03.009

59. Orstavik D. Antibacterial properties of and element release from some dental amalgams. Acta Odontol Scand. 1985;43(4):231-239. doi:10.3109/00016358509046503

60. Hegde NN, Attavar SH, Hegde MN, Priya G. Antibacterial activity of dental restorative material: an in vitro study. J Conserv Dent. $2018 ; 21$ (1):42.doi:10.4103/JCD.JCD_2_17

61. Chatzistavrou X, Lefkelidou A, Papadopoulou L, et al. Bactericidal and bioactive dental composites. Front Physiol. 2018;9:103. doi:10.3389/ fphys.2018.00103

62. Jia H, Hou W, Wei L, et al. The structures and antibacterial properties of nano-SiO2 supported silver/zinc-silver materials. Dent Mater. 2008;24 (2):244-249. doi:10.1016/j.dental.2007.04.015

63. Kasraei S, Sami L, Hendi S, et al. Antibacterial properties of composite resins incorporating silver and zinc oxide nanoparticles on Streptococcus mutans and Lactobacillus. Restor Dent Endod. 2014;39(2):109-114. doi:10.5395/rde.2014.39.2.109

64. Cao W, Zhang Y, Wang X, et al. Development of a novel resin-based dental material with dual biocidal modes and sustained release of Ag+ ions based on photocurable core-shell AgBr/cationic polymer nanocomposites. J Mater Sci Mater Med. 2017;28(7):103. doi:10.1007/s10856-0175918-3

65. Barot T, Rawtani D, Kulkarni P. Physicochemical and biological assessment of silver nanoparticles immobilized Halloysite nanotubes-based resin composite for dental applications. Heliyon. 2020;6(3):e03601. doi:10.1016/j.heliyon.2020.e03601

66. Ren L, Pan Y, Liang Q, et al. In situ synthesis of dental resin matrix containing silver nanoparticles. J Nanosci Nanotechnol. 2019;19 (9):5774-5782. doi:10.1166/jnn.2019.16507

67. Ai M, Du Z, Zhu S, et al. Composite resin reinforced with silver nanoparticles-laden hydroxyapatite nanowires for dental application. Dent Mater. 2017;33(1):12-22. doi:10.1016/j.dental.2016.09.038

68. Dutra-Correa M, Leite AABV, de Cara SPHM, et al. Antibacterial effects and cytotoxicity of an adhesive containing low concentration of silver nanoparticles. J Dent. 2018;77:66-71. doi:10.1016/j.jdent.2018.07.010

69. Sonesson M, Bergstrand F, Gizani S, et al. Management of post-orthodontic white spot lesions: an updated systematic review. Eur J Orthod. 2017;39(2):116-121. doi:10.1093/ejo/cjw023

70. Najafi HZ, Azadeh N, Motamedifar M. Evaluation of the preventive effect of composites containing silver and TiO(2) nanoparticles on demineralization around orthodontic brackets. J Contemp Dent Pract. 2020;21(8):874-879. doi:10.5005/jp-journals-10024-2903

71. Mirhashemi A, Bahador A, Sodagar A, et al. Evaluation of antimicrobial properties of nano-silver particles used in orthodontics fixed retainer composites: an experimental in-vitro study. J Dent Res Dent Clin Dent Prospects. 2021;15(2):87-93. doi:10.34172/joddd.2021.015

72. Sánchez-Tito M, Tay LY. Antibacterial and white spot lesions preventive effect of an orthodontic resin modified with silver-nanoparticles. $J$ Clin Exp Dent. 2021;13(7):e685-e691. doi:10.4317/jced.58330

73. Fatani EJ, Almutairi HH, Alharbi AO, et al. In vitro assessment of stainless steel orthodontic brackets coated with titanium oxide mixed Ag for anti-adherent and antibacterial properties against Streptococcus mutans and Porphyromonas gingivalis. Microb Pathog. 2017;112:190-194. doi:10.1016/j.micpath.2017.09.052

74. Metin-Gürsoy G, Taner L, Akca G. Nanosilver coated orthodontic brackets: in vivo antibacterial properties and ion release. Eur J Orthod. 2017;39(1):9-16. doi:10.1093/ejo/cjv097

75. Haghgoo R, Saderi H, Eskandari M, et al. Evaluation of the antimicrobial effect of conventional and nanosilver-containing varnishes on oral streptococci. J Dent (Shiraz). 2014;15(2):57-62.

76. Burgess JO, Vaghela PM. Silver diamine fluoride: a successful anticarious solution with limits. Adv Dent Res. 2018;29(1):131-134 doi: $10.1177 / 0022034517740123$

77. Crystal YO, Niederman R. Silver diamine fluoride treatment considerations in children's caries management. Pediatr Dent. 2016;38 (7):466-471.

78. Braga MM, Mendes FM, De Benedetto MS, et al. Effect of silver diammine fluoride on incipient caries lesions in erupting permanent first molars: a pilot study. J Dent Child (Chic). 2009;76(1):28-33. 
79. Duangthip D, Chu CH, Lo EC. A randomized clinical trial on arresting dentine caries in preschool children by topical fluorides-18 month results. J Dent. 2016;44:57-63. doi:10.1016/j.jdent.2015.05.006

80. Rosenblatt A, Stamford TC, Niederman R. Silver diamine fluoride: a caries "silver-fluoride bullet". J Dent Res. 2009;88(2):116-125. doi: $10.1177 / 0022034508329406$

81. Urquhart O, Tampi MP, Pilcher L, et al. Nonrestorative treatments for caries: systematic review and network meta-analysis. J Dent Res. 2019;98 (1):14-26. doi:10.1177/0022034518800014

82. Crystal YO, Niederman R. Evidence-based dentistry update on silver diamine fluoride. Dent Clin North Am. 2019;63(1):45-68. doi:10.1016/j. cden.2018.08.011

83. Tirupathi S, Nirmala SVSG, Rajasekhar S, Nuvvula S. Comparative cariostatic efficacy of a novel Nano-silver fluoride varnish with $38 \%$ silver diamine fluoride varnish a double-blind randomized clinical trial. J Clin Exp Dent. 2019;11(2):e105-e112. doi:10.4317/jced.54995

84. Kanwal N, Brauer DS, Earl J, et al. In-vitro apatite formation capacity of a bioactive glass - containing toothpaste. J Dent. 2018;68:51-58. doi:10.1016/j.jdent.2017.10.015

85. Saafan A, Zaazou MH, Sallam MK, et al. Assessment of photodynamic therapy and nanoparticles effects on caries models. Open Access Maced J Med Sci. 2018;6(7):1289-1295. doi:10.3889/oamjms.2018.241

86. Shrestha A, Kishen A. Antibacterial nanoparticles in endodontics: a review. J Endod. 2016;42(10):1417-1426. doi:10.1016/j.joen.2016.05.021

87. Raura NA-O, Garg A, Arora A, et al. Nanoparticle technology and its implications in endodontics: a review. Biomater Res. 2020;24(1):21. doi:10.1186/s40824-020-00198-Z

88. Afkhami F, Akbari S, Chiniforush N. Entrococcus faecalis elimination in root canals using silver nanoparticles, photodynamic therapy, diode laser, or laser-activated nanoparticles: an in vitro study. J Endod. 2017;43(2):279-282. doi:10.1016/j.joen.2016.08.029

89. Chávez-Andrade GM, Tanomaru-Filho M, Rodrigues EM, et al. Cytotoxicity, genotoxicity and antibacterial activity of poly(vinyl alcohol)-coated silver nanoparticles and farnesol as irrigating solutions. Arch Oral Biol. 2017;84:89-93. doi:10.1016/j. archoralbio.2017.09.028

90. Jowkar Z, Hamidi SA, Shafiei F, et al. The effect of silver, zinc oxide, and titanium dioxide nanoparticles used as final irrigation solutions on the fracture resistance of root-filled teeth. Clin Cosmet Investig Dent. 2020;12:141-148. doi:10.2147/CCIDE.S253251

91. Rodrigues CT, de Andrade FB, de Vasconcelos LRSM, et al. Antibacterial properties of silver nanoparticles as a root canal irrigant against Enterococcus faecalis biofilm and infected dentinal tubules. Int Endod J. 2018;51(8):901-911. doi:10.1111/iej.12904

92. Tonini R, Giovarruscio M, Gorni F, et al. In vitro evaluation of antibacterial properties and Smear layer removal/sealer penetration of a novel silver-citrate root canal irrigant. Materials (Basel). 2020;13(1):194. doi:10.3390/ma13010194

93. Generali L, Bertoldi C, Bidossi A, et al. Evaluation of cytotoxicity and antibacterial activity of a new class of silver citrate-based compounds as endodontic irrigants. Materials (Basel). 2020;13(21):5019. doi:10.3390/ma13215019

94. Abrar E, Naseem M, Baig QA, et al. Antimicrobial efficacy of silver diamine fluoride in comparison to photodynamic therapy and chlorhexidine on canal disinfection and bond strength to radicular dentin. Photodiagnosis Photodyn Ther. 2020;32:102066. doi:10.1016/j. pdpdt.2020.102066

95. Al-Madi EM, Al-Jamie MA, Al-Owaid NM, et al. Antibacterial efficacy of silver diamine fluoride as a root canal irrigant. Clin Exp Dent Res. 2019;5(5):551-556. doi:10.1002/cre2.222

96. Shafiei F, Memarpour M, Jowkar Z. Effect of silver antibacterial agents on bond strength of fiber posts to root dentin. Braz Dent J. 2020;31 (4):409-416. doi:10.1590/0103-6440202003300

97. Mishra P, Tyagi S. Surface analysis of gutta percha after disinfecting with sodium hypochlorite and silver nanoparticles by atomic force microscopy: an in vitro study. Dent Res J (Isfahan). 2018;15(4):242-247.

98. Jonaidi-Jafari N, Izadi M, Javidi P. The effects of silver nanoparticles on antimicrobial activity of ProRoot mineral trioxide aggregate (MTA) and calcium enriched mixture (CEM). J Clin Exp Dent. 2016;8(1):e22-6. doi:10.4317/jced.52568

99. Vazquez-Garcia F, Tanomaru-Filho M, Chávez-Andrade GM, et al. Effect of silver nanoparticles on physicochemical and antibacterial properties of calcium silicate cements. Braz Dent J. 2016;27(5):508-514. doi:10.1590/0103-6440201600689

100. Samiei M, Ghasemi N, Asl-Aminabadi N, et al. Zeolite-silver-zinc nanoparticles: biocompatibility and their effect on the compressive strength of mineral trioxide aggregate. J Clin Exp Dent. 2017;9(3):e356-e360. doi:10.4317/jced.53392

101. Donnermeyer D, Bürklein S, Dammaschke T, et al. Endodontic sealers based on calcium silicates: a systematic review. Odontology. 2019;107 (4):421-436. doi:10.1007/s10266-018-0400-3

102. Loyola-Rodríguez JP, Torres-Méndez F, Espinosa-Cristobal LF, et al. Antimicrobial activity of endodontic sealers and medications containing chitosan and silver nanoparticles against Enterococcus faecalis. J Appl Biomater Funct Mater. 2019;17(3):2280800019851771. doi:10.1177/ 2280800019851771

103. Shashirekha G, Jena A, Mohapatra S. Nanotechnology in dentistry: clinical applications, benefits, and hazards. Compend Contin Educ Dent. 2017;38(5):e1-e4.

104. Haghgoo R, Ahmadvand M, Nyakan M, et al. Antimicrobial efficacy of mixtures of nanosilver and zinc oxide eugenol against Enterococcus faecalis. J Contemp Dent Pract. 2017;18(3):177-181. doi:10.5005/jp-journals-10024-2012

105. Vilela Teixeira AB, de Carvalho Honorato Silva C, Alves OL, et al. Endodontic sealers modified with silver vanadate: antibacterial, compositional, and setting time evaluation. Biomed Res Int. 2019;2019:4676354. doi:10.1155/2019/4676354

106. Teixeira ABV, de Castro DT, Schiavon MA, et al. Cytotoxicity and release ions of endodontic sealers incorporated with a silver and vanadium base nanomaterial. Odontology. 2020;108(4):661-668. doi:10.1007/s10266-020-00507-x

107. Baras BH, Melo MAS, Sun J, et al. Novel endodontic sealer with dual strategies of dimethylaminohexadecyl methacrylate and nanoparticles of silver to inhibit root canal biofilms. Dent Mater. 2019;35(8):1117-1129. doi:10.1016/j.dental.2019.05.014

108. Accardo C, Himel VT, Lallier TE. A novel GuttaFlow sealer supports cell survival and attachment. $J$ Endod. 2014;40(2):231-234. doi:10.1016/ j.joen.2013.08.029

109. Martinho FC, Camargo SEA, Fernandes AMM, et al. Comparison of cytotoxicity, genotoxicity and immunological inflammatory biomarker activity of several endodontic sealers against immortalized human pulp cells. Int Endod J. 2018;51(1):41-57. doi:10.1111/iej.12785

110. Marica A, Fritea L, Banica F, et al. Carbon nanotubes for improved performances of endodontic sealer. Materials (Basel). 2021;14(15):4248. doi:10.3390/ma14154248 
111. Sanz M, Marco Del Castillo A, Jepsen S, et al. Periodontitis and cardiovascular diseases: consensus report. J Clin Periodontol. 2020;47 (3):268-288. doi:10.1111/jcpe.13189

112. Herrera D, Alonso B, León R, et al. Antimicrobial therapy in periodontitis: the use of systemic antimicrobials against the subgingival biofilm. $J$ Clin Periodontol. 2008;35(8 Suppl):45-66. doi:10.1111/j.1600-051X.2008.01260.x

113. Panáček A, Smékalová $M$, Večeřová R, et al. Silver nanoparticles strongly enhance and restore bactericidal activity of inactive antibiotics against multiresistant Enterobacteriaceae. Colloids Surf B Biointerfaces. 2016;142:392-399. doi:10.1016/j.colsurfb.2016.03.007

114. Prasetyo B, Sugiharti RJ, Mahendra I, et al. Evaluation of silver nanoparticles addition in periodontal dressing for wound tissue healing by 99mTc-ciprofloxacin. J Young Pharm. 2018;11(1):17-20. doi:10.5530/jyp.2019.11.4

115. Li D, Qiu Y, Zhang S, et al. A multifunctional antibacterial and osteogenic nanomedicine: QAS-modified core-shell mesoporous silica containing Ag nanoparticles. Biomed Res Int. 2020;2020:4567049. doi:10.1155/2020/4567049

116. Shao J, Yu N, Kolwijck E, et al. Biological evaluation of silver nanoparticles incorporated into chitosan-based membranes. Nanomedicine (Lond). 2017;12(22):2771-2785. doi:10.2217/nnm-2017-0172

117. Lee D, Lee SJ, Moon JH, et al. Preparation of antibacterial chitosan membranes containing silver nanoparticles for dental barrier membrane applications. Int J Dev Disabil. 2018;66:196-202. doi:10.1080/20473869.2018.1544969

118. Qian Y, Zhou X, Zhang F, et al. Triple PLGA/PCL Scaffold modification including silver impregnation, collagen coating, and electrospinning significantly improve biocompatibility, antimicrobial, and osteogenic properties for orofacial tissue regeneration. ACS Appl Mater Interfaces. 2019;11(41):37381-37396. doi:10.1021/acsami.9b07053

119. Gad MM, Fouda S, Al-Harbi F, et al. PMMA denture base material enhancement: a review of fiber, filler, and nanofiller addition. Int J Nanomedicine. 2017;12:3801-3812. doi:10.2147/IJN.S130722

120. Bacali C, Baldea I, Moldovan M, et al. Flexural strength, biocompatibility, and antimicrobial activity of a polymethyl methacrylate denture resin enhanced with graphene and silver nanoparticles. Clin Oral Investig. 2020;24(8):2713-2725. doi:10.1007/s00784-019-03133-2

121. Zhang Y, Chen -Y-Y, Huang L, et al. The antifungal effects and mechanical properties of silver bromide/cationic polymer nano-compositemodified Poly-methyl methacrylate-based dental resin. Sci Rep. 2017;7(1):1547. doi:10.1038/s41598-017-01686-4

122. Kagami K, Abe Y, Shinonaga Y, et al. Antibacterial and antifungal activities of PMMAs implanted fluorine and/or silver ions by plasma-based ion implantation with argon. Materials (Basel). 2020;13(20):4525. doi:10.3390/ma13204525

123. Gad MM, Abualsaud R, Rahoma A, et al. Double-layered acrylic resin denture base with nanoparticle additions: an in vitro study. $J$ Prosthet Dent. 2022;127:174-183.doi:10.1016/j.prosdent.2020.08.021

124. Suganya S, Ahila SC, Kumar B, et al. Evaluation and comparison of anti-Candida effect of heat cure polymethylmethacrylate resin enforced with silver nanoparticles and conventional heat cure resins: an in vitro study. Indian J Dent Res. 2014;25(2):204-207. doi:10.4103/09709290.135923

125. Li Z, Sun J, Lan J, et al. Effect of a denture base acrylic resin containing silver nanoparticles on Candida albicans adhesion and biofilm formation. Gerodontology. 2016;33(2):209-216. doi:10.1111/ger.12142

126. Chen S, Yang J, Jia Y-G, et al. A study of 3D-printable reinforced composite resin: PMMA modified with silver nanoparticles loaded cellulose nanocrystal. Materials (Basel). 2018;11(12):2444. doi:10.3390/ma11122444

127. Swathy JR, Sankar MU, Chaudhary A, Aigal S, Pradeep T. Antimicrobial silver: an unprecedented anion effect. Sci Rep. 2014;4(1):7161. doi:10.1038/srep07161

128. Yoshihara K, Nagaoka N, Umeno A, et al. Antibacterial effect of amino acid-silver complex loaded montmorillonite incorporated in dental acrylic resin. Materials (Basel). 2021;14(6):1442. doi:10.3390/ma14061442

129. Yoshida Y, Churei $\mathrm{H}$, Takeuchi $\mathrm{Y}$, et al. Novel antibacterial mouthguard material manufactured using silver-nanoparticle-embedded ethylene-vinyl acetate copolymer masterbatch. Dent Mater J. 2018;37(3):437-444. doi:10.4012/dmj.2017-226

130. Ginjupalli K, Alla RK, Tellapragada C, et al. Antimicrobial activity and properties of irreversible hydrocolloid impression materials incorporated with silver nanoparticles. J Prosthet Dent. 2016;115(6):722-728. doi:10.1016/j.prosdent.2015.11.006

131. Fujieda T, Uno M, Ishigami H, et al. Addition of platinum and silver nanoparticles to toughen dental porcelain. Dent Mater J. 2012;31 (5):711-716. doi: $10.4012 / \mathrm{dmj} .2012-044$

132. Fujieda T, Uno M, Ishigami H, et al. Effects of dental porcelain containing silver nanoparticles on static fatigue. Dent Mater J. 2013;32 (3):405-408. doi:10.4012/dmj.2012-266

133. Schwarz F, Derks J, Monje A, et al. Peri-implantitis. J Periodontol. 2018;89(Suppl 1):S267-s290. doi:10.1002/JPER.16-0350

134. Dong H, Liu H, Zhou N, et al. Surface modified techniques and emerging functional coating of dental implants. Coatings. 2020;10(11):1012. doi:10.3390/coatings 10111012

135. Sobolev A, Valkov A, Kossenko A, et al. Bioactive coating on Ti alloy with high osseointegration and antibacterial Ag nanoparticles. ACS Appl Mater Interfaces. 2019;11(43):39534-39544. doi:10.1021/acsami.9b13849

136. Choi S, Jang Y-S, Jang J-H, et al. Enhanced antibacterial activity of titanium by surface modification with polydopamine and silver for dental implant application. J Appl Biomater Funct Mater. 2019;17(3):2280800019847067. doi:10.1177/2280800019847067

137. Pokrowiecki R, Zareba T, Szaraniec B, et al. In vitro studies of nanosilver-doped titanium implants for oral and maxillofacial surgery. Int J Nanomedicine. 2017;12:4285-4297. doi:10.2147/IJN.S131163

138. Gunputh UF, Le H, Lawton K, et al. Antibacterial properties of silver nanoparticles grown in situ and anchored to titanium dioxide nanotubes on titanium implant against Staphylococcus aureus. Nanotoxicology. 2020;14(1):97-110. doi:10.1080/17435390.2019.1665727

139. Shimabukuro M. Antibacterial property and biocompatibility of silver, copper, and zinc in titanium dioxide layers incorporated by one-step micro-arc oxidation: a review. Antibiotics (Basel). 2020;9(10). doi:10.3390/antibiotics9100716

140. Okuzu Y, Fujibayashi S, Yamaguchi S, et al. In vitro study of antibacterial and osteogenic activity of titanium metal releasing strontium and silver ions. J Biomater Appl. 2021;35(6):670-680. doi:10.1177/0885328220959584

141. Guo C, Cui W, Wang X, et al. Poly-l-lysine/sodium alginate coating loading nanosilver for improving the antibacterial effect and inducing mineralization of dental implants. ACS Omega. 2020;5(18):10562-10571. doi:10.1021/acsomega.0c00986

142. Qiao S, Cao H, Zhao X, et al. Ag-plasma modification enhances bone apposition around titanium dental implants: an animal study in Labrador dogs. Int J Nanomedicine. 2015;10:653-664. doi:10.2147/IJN.S73467 
143. Agnihotri S, Mukherji S, Mukherji S. Immobilized silver nanoparticles enhance contact killing and show highest efficacy: elucidation of the mechanism of bactericidal action of silver. Nanoscale. 2013;5(16):7328-7340. doi:10.1039/c3nr00024a

144. Massa MA, Covarrubias C, Bittner M, et al. Synthesis of new antibacterial composite coating for titanium based on highly ordered nanoporous silica and silver nanoparticles. Mater Sci Eng C Mater Biol Appl. 2014;45:146-153. doi:10.1016/j.msec.2014.08.057

145. Györgyey Á, Janovák L, Ádám A, et al. Investigation of the in vitro photocatalytic antibacterial activity of nanocrystalline TiO2 and coupled $\mathrm{TiO} / \mathrm{Ag}$ containing copolymer on the surface of medical grade titanium. J Biomater Appl. 2016;31(1):55-67. doi:10.1177/0885328216633374

146. Matsubara VH, Igai F, Tamaki R, et al. Use of silver nanoparticles reduces internal contamination of external hexagon implants by Candida albicans. Braz Dent J. 2015;26(5):458-462. doi:10.1590/0103-644020130087

147. Zhang Y, Zheng Z, Yu M, et al. Using an engineered galvanic redox system to generate positive surface potentials that promote osteogenic functions. ACS Appl Mater Interfaces. 2018;10(18):15449-15460. doi:10.1021/acsami.8b02798

148. Liu X, Gan K, Liu H, et al. Antibacterial properties of nano-silver coated PEEK prepared through magnetron sputtering. Dent Mater. 2017;33 (9):e348-e360. doi:10.1016/j.dental.2017.06.014

149. Yamada R, Nozaki K, Horiuchi N, et al. Ag nanoparticle-coated zirconia for antibacterial prosthesis. Mater Sci Eng C Mater Biol Appl. 2017;78:1054-1060. doi:10.1016/j.msec.2017.04.149

150. Chen P, Wu Z, Leung A, et al. Fabrication of a silver nanoparticle-coated collagen membrane with anti-bacterial and anti-inflammatory activities for guided bone regeneration. Biomed Mater. 2018;13(6):065014. doi:10.1088/1748-605X/aae15b

151. Selvido DA-O, Bhattarai BP, Riddhabhaya A, Vongsawan K, Arunpraphan S, Wongsirichat N. A review on the application of silver nanoparticles in oral and maxillofacial surgery. Eur J Dent. 2021. doi:10.1055/s-0041-1731589

152. Canellas J, Fraga SRG, Santoro MF, et al. Intrasocket interventions to prevent alveolar osteitis after mandibular third molar surgery: a systematic review and network meta-analysis. J Craniomaxillofac Surg. 2020;48(9):902-913. doi:10.1016/j.jcms.2020.06.012

153. Dong Y, Liu W, Lei Y, et al. Effect of gelatin sponge with colloid silver on bone healing in infected cranial defects. Mater Sci Eng C Mater Biol Appl. 2017;70(Pt 1):371-377. doi:10.1016/j.msec.2016.09.015

154. Dumville JC, Gray TA, Walter CJ, et al. Dressings for the prevention of surgical site infection. Cochrane Database Syst Rev. 2016;12(12): Cd003091. doi:10.1002/14651858.CD003091.pub4

155. Jeong L, Kim MH, Jung J-Y, et al. Effect of silk fibroin nanofibers containing silver sulfadiazine on wound healing. Int J Nanomedicine. 2014;9:5277-5287. doi:10.2147/IJN.S71295

156. Gallo AL, Paladini F, Romano A, et al. Efficacy of silver coated surgical sutures on bacterial contamination, cellular response and wound healing. Mater Sci Eng C Mater Biol Appl. 2016;69:884-893. doi:10.1016/j.msec.2016.07.074

157. Syukri DM, Nwabor OF, Singh S, et al. Antibacterial-coated silk surgical sutures by ex situ deposition of silver nanoparticles synthesized with Eucalyptus camaldulensis eradicates infections. J Microbiol Methods. 2020;174:105955. doi:10.1016/j.mimet.2020.105955

158. De Simone S, Gallo AL, Paladini F, et al. Development of silver nano-coatings on silk sutures as a novel approach against surgical infections. J Mater Sci Mater Med. 2014;25(9):2205-2214. doi:10.1007/s10856-014-5262-9

159. Baygar T, Sarac N, Ugur A, et al. Antimicrobial characteristics and biocompatibility of the surgical sutures coated with biosynthesized silver nanoparticles. Bioorg Chem. 2019;86:254-258. doi:10.1016/j.bioorg.2018.12.034

160. Zheng DW, Deng -W-W, Song W-F, et al. Biomaterial-mediated modulation of oral microbiota synergizes with PD-1 blockade in mice with oral squamous cell carcinoma. Nat Biomed Eng. 2021. doi:10.1038/s41551-021-00807-9

International Journal of Nanomedicine

\section{Publish your work in this journal}

The International Journal of Nanomedicine is an international, peer-reviewed journal focusing on the application of nanotechnology in diagnostics, therapeutics, and drug delivery systems throughout the biomedical field. This journal is indexed on PubMed Central, MedLine, CAS, SciSearch ${ }^{\circledR}$, Current Contents ${ }^{\mathbb{B}} /$ Clinical Medicine, Journal Citation Reports/Science Edition, EMBase, Scopus and the Elsevier Bibliographic databases. The manuscript management system is completely online and includes a very quick and fair peer-review system, which is all easy to use. Visit http:// www.dovepress.com/testimonials.php to read real quotes from published authors.

Submit your manuscript here: https://www.dovepress.com/international-journal-of-nanomedicine-journal 